\title{
Atherogenesis and iron: from epidemiology to cellular level
}

\author{
Francesca Vinchi ${ }^{1,2}$, Martina U. Muckenthaler ${ }^{1,2}$, Milene C. Da Silva ${ }^{1,2}$, György Balla ${ }^{3,4}$, József Balla ${ }^{5}$ \\ and Viktória Jeney ${ }^{3,5 *}$
}

${ }^{1}$ Department of Pediatric Oncology, Hematology and Immunology, University of Heidelberg, Heidelberg, Germany

${ }^{2}$ Molecular Medicine and Partnership Unit, University of Heidelberg, Heidelberg, Germany

${ }^{3}$ MTA-DE Vascular Biology, Thrombosis and Hemostasis Research Group, Hungarian Academy of Sciences, Debrecen, Hungary

${ }^{4}$ Department of Pediatrics, University of Debrecen, Debrecen, Hungary

${ }^{5}$ Department of Medicine, University of Debrecen, Debrecen, Hungary

\section{Edited by:}

Raffaella Gozzelino, Instituto Gulbenkian de Ciência, Portugal

Reviewed by:

Andrei Adrian Tica, University of Medicine Craiova Romania, Romania

Gregory M. Vercellotti, University of

Minnesota, USA

*Correspondence:

Viktoria Jeney, Department of

Medicine, University of Debrecen,

Nagyerdei krt. 98, Debrecen 4012,

Hungary

e-mail:jeneyv@

internal.med.unideb.hu
Iron accumulates in human atherosclerotic lesions but whether it is a cause or simply a downstream consequence of the atheroma formation has been an open question for decades. According to the so called "iron hypothesis," iron is believed to be detrimental for the cardiovascular system, thus promoting atherosclerosis development and progression. Iron, in its catalytically active form, can participate in the generation of reactive oxygen species and induce lipid-peroxidation, triggering endothelial activation, smooth muscle cell proliferation and macrophage activation; all of these processes are considered to be proatherogenic. On the other hand, the observation that hemochromatotic patients, affected by life-long iron overload, do not show any increased incidence of atherosclerosis is perceived as the most convincing evidence against the "iron hypothesis." Epidemiological studies and data from animal models provided conflicting evidences about the role of iron in atherogenesis. Therefore, more careful studies are needed in which issues like the source and the compartmentalization of iron will be addressed. This review article summarizes what we have learnt about iron and atherosclerosis from epidemiological studies, animal models and cellular systems and highlights the rather contributory than innocent role of iron in atherogenesis.

Keywords: atherosclerosis, iron, hemoglobin, heme, intraplaque hemorrhage, LDL, oxidative stress, macrophages

\section{INTRODUCTION}

\section{A ROLE FOR IRON IN ATHEROSCLEROSIS: THE "IRON HYPOTHESIS"}

The correlation between iron and heart disease was initially proposed by Sullivan in 1981. According to his "iron hypothesis," iron overload promotes cardiovascular disease, while on the contrary, sustained iron depletion/deficiency exerts a primary protective effect against ischemic heart disease. This theory, continually debated for more than 30 years, was based on the observation that male gender is associated with higher risk of cardiovascular disease, but that the protective effect in women is diminished after menopause (Sullivan, 1981, 1989). Based on results from the Framingham study (Kannel et al., 1976), Sullivan first hypothesized that the regular menstrual loss of iron, rather than the effect of estrogen, protects women against coronary heart disease (CHD). The failure of postmenopausal estrogen replacement to prevent coronary events further supported the iron hypothesis and its link to gender differences in atherosclerosis (Hulley et al., 1998).

The presence of redox-active iron, as well as high expression levels of $\mathrm{H}$ - and L-ferritin in human atherosclerotic lesions provided indirect support for the iron hypothesis (Smith et al., 1992; Pang et al., 1996). L-ferritin levels are increased in coronary arteries from patients with coronary artery disease (CAD), indicating that iron accumulates in atherosclerotic plaques (You et al., 2003). Additionally, cholesterol levels in lesions correlate with iron deposits (Stadler et al., 2004). Within the plaque, iron deposition and ferritin induction may be observed in endothelial cells and macrophages in early human lesions, and additionally in vascular smooth muscle cells (VSMCs) in late lesions.

Iron accumulates in human atherosclerotic lesions (Sullivan, 2009) via different mechanisms. Under normal conditions iron circulates in the bloodstream bound to its carrier protein transferrin (Tf). However, non-transferrin bound iron (NTBI) may be generated during chronic iron overload disorders such as sickle cell disease, thalassemia and transfusional iron overload (Brissot et al., 2012). NTBI is thought to be easily accessible to many cell types within the plaque, likely accumulating in endothelial cells, macrophages, and VSMCs (Figure 1).

Iron can enter into the atherosclerotic lesion in the form of free hemoglobin $(\mathrm{Hb})$, that is released upon intravascular hemolysis or intraplaque hemorrhage (Kolodgie et al., 2003). Intraplaque hemorrhage originates from leaky neovessels invading the intima from the vasa vasorum as the intima thicken, and contributes significantly to the enlargement of the necrotic core (Sakakura et al., 2013). Increasing evidence indicates that plaque neovascularization and vasa vasorum density accompanied by intraplaque hemorrhage is a strong marker for plaque vulnerability (Moreno et al., 2004; Carlier et al., 2005; Virmani et al., 2005; Michel et al., 2011; Sakakura et al., 2013). Following intraplaque hemorrhage, red cells can be taken up by macrophages or they burst extracellularly releasing free $\mathrm{Hb}$. $\mathrm{Hb}$ is prone to oxidation, especially in the highly oxidative milieu of the atheroma leading to the formation 


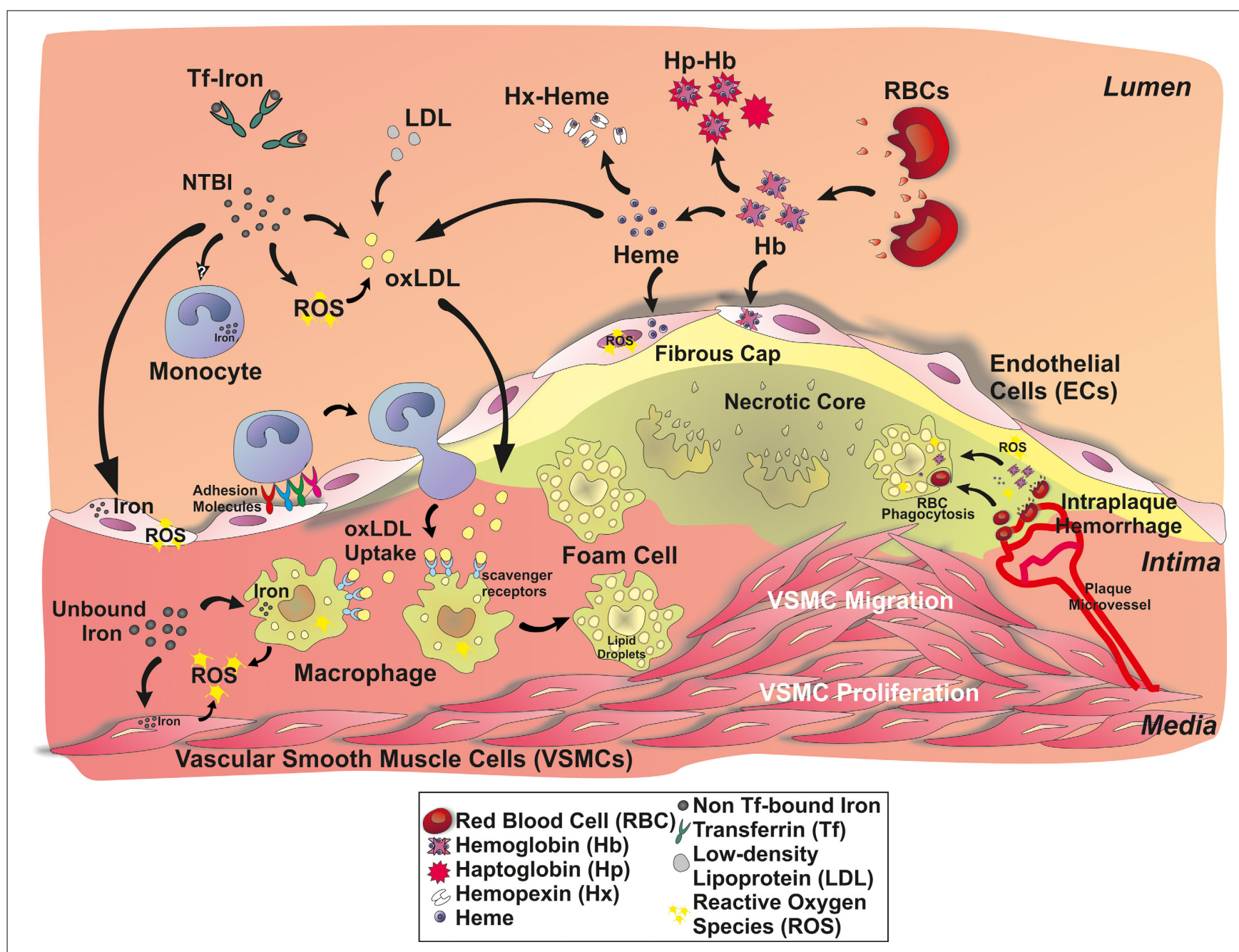

FIGURE 1 | A role for iron in atherosclerotic lesions. Iron accumulates in the plaque either as inorganic or hemoglobin-bound iron. Inorganic iron in part derives from circulating transferrin (Tf)-bound iron and non-transferrin-bound iron (NTBI). NTBI is generated in chronic iron overload conditions, such as in iron-loading anemia, hereditary hemochromatosis or secondary hemochromatosis due to blood transfusions. Circulating NTBI is accessible to many cell types in the atherosclerotic plaque: endothelial cells,

monocytes/macrophages, and vascular smooth muscle cells (VSMCs).
Hemoglobin- and heme-derived iron can access the plaque upon intravascular hemolysis and intraplaque hemorrhage, affecting endothelial cells and macrophages. Hemoglobin ( $\mathrm{Hb})$, heme and iron promote endothelial activation, by enhancing adhesion molecule expression. As a consequence, monocyte recruitment is expected to be increased. Circulating iron and $\mathrm{Hb}$ oxidize LDLs, thus enhancing subendothelial LDL retention and macrophage progression to foam cells. Iron also affects VSMC proliferation and migration into the lesion, favoring plaque progression. of metHb and higher oxidation states such as ferrylHb, which can release heme (Figure 1). Altogether, Hb oxidation products, heme and iron exert pro-oxidant and pro-inflammatory effects targeting different cellular (i.e., endothelial cells, smooth muscle cells, macrophages) and acellular components (i.e., low-density lipoprotein, LDL) of the atherosclerotic vessel wall (Figure 1).

The finding that human atherosclerotic plaques contain redoxactive iron, that could promote free radical formation and lipid peroxidation, further suggested a role for iron in atherosclerosis that may be eventually responsible for progressive oxidative damage in atherosclerotic lesions. This review article summarizes our current knowledge about the role of $\mathrm{Hb}$, heme, and iron in atherosclerosis by discussing the results of epidemiological studies, and observations in animal models and cellular experiments.

\section{ALTERED IRON HOMEOSTASIS AND ATHEROSCLEROSIS: EPIDEMIOLOGICAL STUDIES, HUMAN CASES CORRELATION BETWEEN MARKERS OF IRON STORES AND DEVELOPMENT OF CAD}

To evaluate whether iron accumulation in the atherosclerotic plaque is a cause, rather than a consequence, of cardiovascular disease, several epidemiological and perspective studies were conducted since the nineties and many are still ongoing.

The results of several human studies strongly suggested a relationship between body iron levels and atherosclerosis. According to these epidemiological studies, high systemic iron levels, monitored by serum ferritin levels or transferrin saturation, positively correlated with increased risk of myocardial infarction (Salonen et al., 1992; Morrison et al., 1994; Tuomainen et al., 1998; 
Holay et al., 2012) cardiovascular disease (Rajapurkar et al., 2011), peripheral arterial disease (PAD) (Menke et al., 2009), and mortality rates (Lauffer, 1990). This association was stronger in men with high serum LDL levels, suggesting a synergistic role of high iron and high LDL levels (Salonen et al., 1992; Morrison et al., 1994). Finally, a clear proatherogenic role for iron was suggested by the observation that a $10 \mathrm{mg} / \mathrm{L}$ increase in serum ferritin level raised the probability of having at least two atherosclerotic plaques by 3\% (Ahluwalia et al., 2010).

Body iron stores correlated with asymptomatic carotid atherosclerosis in healthy men (Syrovatka et al., 2011), an association becomes even more evident in symptomatic atherosclerosis. Plaques from symptomatic patients showed higher iron concentrations, signs of cap rupture and increased cap macrophage activity compared with asymptomatic plaques (Gustafsson et al., 2013). This suggests that the presence of iron in carotid plaques positively correlates with plaque vulnerability for rupture.

Additionally, the description of serum ferritin levels as a risk indicator of carotid lesion progression highlights a clear association between atherosclerosis progression and iron stores (Kiechl et al., 1997).

In agreement with this, serum iron levels directly correlate with cardiovascular disease severity. Serum iron levels were significantly higher in patients with severe atherosclerosis compared to those showing normal, mild, and moderate sings of CADs, thus further strengthening the hypothesis that high iron levels could affect atherosclerosis severity (Bagheri et al., 2013). Collectively, these epidemiological studies clearly identified high body iron levels as a risk factor for atherosclerosis and cardiovascular diseases.

Serum ferritin levels are frequently used to assess body iron status but increasing evidence suggests that this parameter additionally serves as a more general marker of inflammation (Kalantar-Zadeh et al., 2004; Manousou et al., 2011). Thus, some studies evaluated the relationships between serum ferritin, inflammatory cytokines and cardiovascular disease (Haidari et al., 2001; Depalma et al., 2010). Ferritin levels positively correlated with IL-6 and C-reactive protein (hsCRP) levels and were higher in patients that died of acute myocardial infarction vs. survivors, further supporting a rationale for measurement of ferritin levels in patients with atherosclerosis.

\section{BLOOD DONATION AND THE RISK OF CAD}

The incidence of atherosclerosis in premenopausal women was less than half of that observed in men of the same age (Kiechl and Willeit, 1999). The sex difference disappeared within 5 years after menopause, likely due to increased body iron stores. According to these observations, in 1991 Sullivan proposed that blood donation could prevent cardiovascular disease (Sullivan, 1991). Several studies confirmed the cardiovascular protective effect of blood donation. Blood donation was positively associated with a reduced risk of cardiovascular disease, in particular in non-smoking men with high serum LDL levels (Meyers et al., 1997, 2002; Tuomainen et al., 1997; Salonen et al., 1998). This result was in agreement with the iron hypothesis, according to which the protective effect of blood donation would be more pronounced in men that have a higher body iron load than women. A first randomized clinical trial (FeAST) showed that phlebotomy resulted in clinical benefits and reduction of death in young patients affected by PAD (Sullivan and Katz, 2007; Zacharski et al., 2007). High-frequency blood donation was associated with reduced body iron stores and improved vascular function and blood pressure, reduced oxidative stress, improved markers of cardiovascular risk in blood donors (Zheng et al., 2005; Houschyar et al., 2012). These findings are complemented by the observation that endothelial dysfunction is attenuated by iron chelation in patient with CAD (Duffy et al., 2001). Altogether these findings suggest that iron depletion, by blood donation or iron chelation, significantly lowers the risk of cardiovascular disease, thus supporting the iron hypothesis.

\section{ASSOCIATION OF IRON OVERLOAD AND CAD IN HEMOCHROMATOSIS}

If the iron hypothesis is correct, individuals with iron overload would be expected to show an increased risk and incidence of cardiovascular diseases, thus being optimal study model to test the validity of the hypothesis.

An interesting observation comes from the study of American blacks that compared to American whites and Hispanics are well known for higher ferritin levels throughout their entire life, likely explained by nutritional and genetic factors rather than increased iron intake (Zacharski et al., 2000). Interestingly, the incidence of CHD is higher in African-American than in white men and women (Gillum et al., 1997; Sacco et al., 1998), suggesting an association between body iron and cardiovascular disease.

Hereditary hemochromatosis $(\mathrm{HH})$ is a genetic disorder associated with progressive iron overload, resulting in oxidative stress and organ failure. $\mathrm{HH}$ is more common among individuals of Northern European descent and is caused by inherited mutations in proteins implicated in iron transport and regulation, such as the upstream regulators of hepcidin, the human hemochromatosis protein (HFE), hemojuvelin, transferrin receptor (TfR)2 , as well as hepcidin and ferroportin (FPN) (Hentze et al., 2010).

Hemochromatotic patients show vascular dysfunction and increased expression of adhesion molecules that positively correlates to iron overload and NTBI levels (Gaenzer et al., 2002; Kartikasari et al., 2006; Van Tits et al., 2007). These patients further show functional and structural alterations in midsize muscle arteries. In particular, arterial wall thickness is increased before the onset of cardiovascular complications, suggesting that this is an early abnormality in $\mathrm{HH}$. This alteration is reverted by phlebotomy-induced iron depletion, which can also improve the endothelium-dependent vasodilation and the initial radial artery wall stiffening associated with HH (Failla et al., 2000; Gaenzer et al., 2002).

Different cohort studies reported a significantly greater risk of myocardial infarction, cerebrovascular mortality and cardiovascular mortality in carriers of the HFE mutation (Cys282Tyr) (Roest et al., 1999; Tuomainen et al., 1999; Rasmussen et al., 2001). Additionally, patients with genetic hemochromatosis have significant eccentric hypertrophy of the radial artery, although not showing arterial hypertension or evidence of cardiovascular disease. 
In contrast to the above reported studies, others failed to find an association between hemochromatosis and the presence or frequency of atherosclerosis and did not succeed in establishing a link between body iron stores and cardiovascular diseases in human populations (Miller and Hutchins, 1994; Sullivan and Zacharski, 2001; Munoz-Bravo et al., 2013). The disagreement among epidemiological studies may result from variations in the validity and reliability of the indicators of iron status. Additionally, the magnitude of the relative risk associated with iron overload might be small, thus the association being obscured by stronger risk factors. Further prospective and experimental studies are needed to confirm the association between the iron status and atherosclerosis.

\section{THE "REFINED IRON HYPOTHESIS": A PROTECTIVE ROLE FOR IRON-DEPLETED MACROPHAGES IN ATHEROSCLEROSIS}

Controversial results from epidemiological studies investigating different types of atherosclerotic events and using various markers for body iron levels present a confusing picture regarding the iron hypothesis. In addition, several studies failed to observe an increased risk or incidence of cardiovascular events in hemochromatotic patients, thus further increasing the confusion concerning an eventual association between iron overload and atherosclerosis (reviewed in Munoz-Bravo et al., 2013). Finally, the description of a potentially protective effect of hemochromatosis against atherosclerosis and cardiovascular diseases was perceived as a "paradox" and considered as clear evidence against the iron hypothesis (Miller and Hutchins, 1994; Sullivan and Zacharski, 2001; Munoz-Bravo et al., 2013). On the basis of these observations Sullivan presented a refinement of his "iron hypothesis" (Sullivan and Zacharski, 2001).

Since then the peptide hormone hepcidin has been identified as the master regulator of iron homeostasis. Hepcidin inhibits iron export by binding to FPN and promoting its degradation. By inhibiting FPN, hepcidin prevents iron release from enterocytes into the bloodstream and decreasing iron release from macrophages, thereby reducing the amount of iron systemically available. $\mathrm{HH}$ is hallmarked by low levels of hepcidin and/or increased expression of the iron exporter FPN. Therefore, in hemochromatotic patients the FPN-hepcidin circuitry is impaired, leading to increased duodenal iron absorption and reduced iron retention in macrophages (Hentze et al., 2010; Ganz and Nemeth, 2011). Considering the key role of the macrophages in atherogenesis, the selective iron depletion in this cell type was proposed as a mechanism of protection against foam cell formation and atherosclerotic lesion progression (Figure 2). According to this view, the hypothesis postulated by Sullivan that iron depletion protects against atherosclerosis may apply even to hemochromatotic individuals.

According to this view, hepcidin levels may act as a potential iron-dependent risk factor for atherosclerosis by regulating macrophage iron accumulation and atherosclerotic plaque progression (Figure 2). Recently, hepcidin was suggested as a predictor of carotid atherosclerosis. Serum ferritin was found to associate with vascular damage, common carotid thickness and presence of carotid plaques in all patients but not those showing a reduction in hepcidin levels due to heterozygous HFE mutations (Valenti et al., 2011b). Additionally, hepcidin levels and macrophage iron positively correlate with the release of IL-6 and macrophage chemoattractant protein 1 (MCP-1), and vascular damage in high-risk individuals (Valenti et al., 2011a). Collectively, these findings suggest an involvement of iron-loaded macrophages in inflammation and vascular alterations. On the other hand, monocytes from hemochromatotic patients showed reduced ability to accumulate iron and reduced upregulation of MCP-1 and IL-6 (Valenti et al., 2011a). The anti-inflammatory properties of iron-depleted macrophages may help to explain the lack of increased incidence of atherosclerosis in hemochromatotic patients.

Anyway, a direct and definitive demonstration of the refined iron hypothesis in human is still lacking and further studies are needed to fully elucidate the impact of macrophage-stored iron, as well as circulating iron and tissue-stored iron on human lesion formation and progression.

\section{THALASSEMIAS AND SICKLE CELL ANEMIA}

$\beta$-thalassemia and sickle cell anemia are hereditary blood disorders characterized by anomalies in the synthesis of the $\beta$-globin chains of $\mathrm{Hb}$. $\beta$-thalassemic and sickle patients show increased plasma iron turnover, iron absorption and tissue iron deposition. Additionally, they have frequent hemolytic events that lead to the release of $\mathrm{Hb}$ and heme into the circulation, further increasing the amount of redox-active iron available for the production of reactive oxygen species and lipid peroxidation (Livrea et al., 1998; Brizzi et al., 2002). The release of $\mathrm{Hb}$ upon hemolytic events and the enhanced absorption of iron, to support inappropriate erythropoiesis, contribute to the pathogenesis of vasculopathy, a well-known predisposing factor for cardiovascular diseases. Moreover, these patients, usually presenting with severe anemia, require regular red blood cell transfusions (Vichinsky, 2005), further exacerbating iron overload and iron-driven oxidative stress (McLeod et al., 2009).

Iron-dependent peroxidative tissue injury results in arterial stiffness and dysfunction, frequently occurring in thalassemic patients (Kremastinos et al., 1999; Hahalis et al., 2008). Iron overload in patients with beta-thalassemia major lead to alterations in the arterial structures and in the thickness of the carotid arteries (Cheung et al., 2002; Tantawy et al., 2009). Moreover, carotid thickness positively correlated with age, $\mathrm{Hb}$, ferritin and cholesterol levels in these patients (Cheung et al., 2006; Tantawy et al., 2009). As a result, CAD is a quite common cardiovascular complication in thalassemia (Ramakrishna et al., 2003; Ferrara and Taylor, 2005; Aessopos et al., 2007). Patients on a regular transfusion regimen progressively develop clinical manifestations of iron overload associated with heart dysfunction and left ventricular failure (Borgna-Pignatti et al., 2004). Interestingly, iron chelation therapy in thalassemia patients improves arterial function and stiffness (Cheung et al., 2008).

Ischemic complications are the major causes of morbidity and mortality in patients with sickle cell disease (Platt et al., 1994; Switzer et al., 2006). Ischemic events in these patients have been attributed to the effects of $\mathrm{Hb}$ polymerization, resulting in sickled cells trapped in the microcirculation (Francis and Johnson, 1991). 


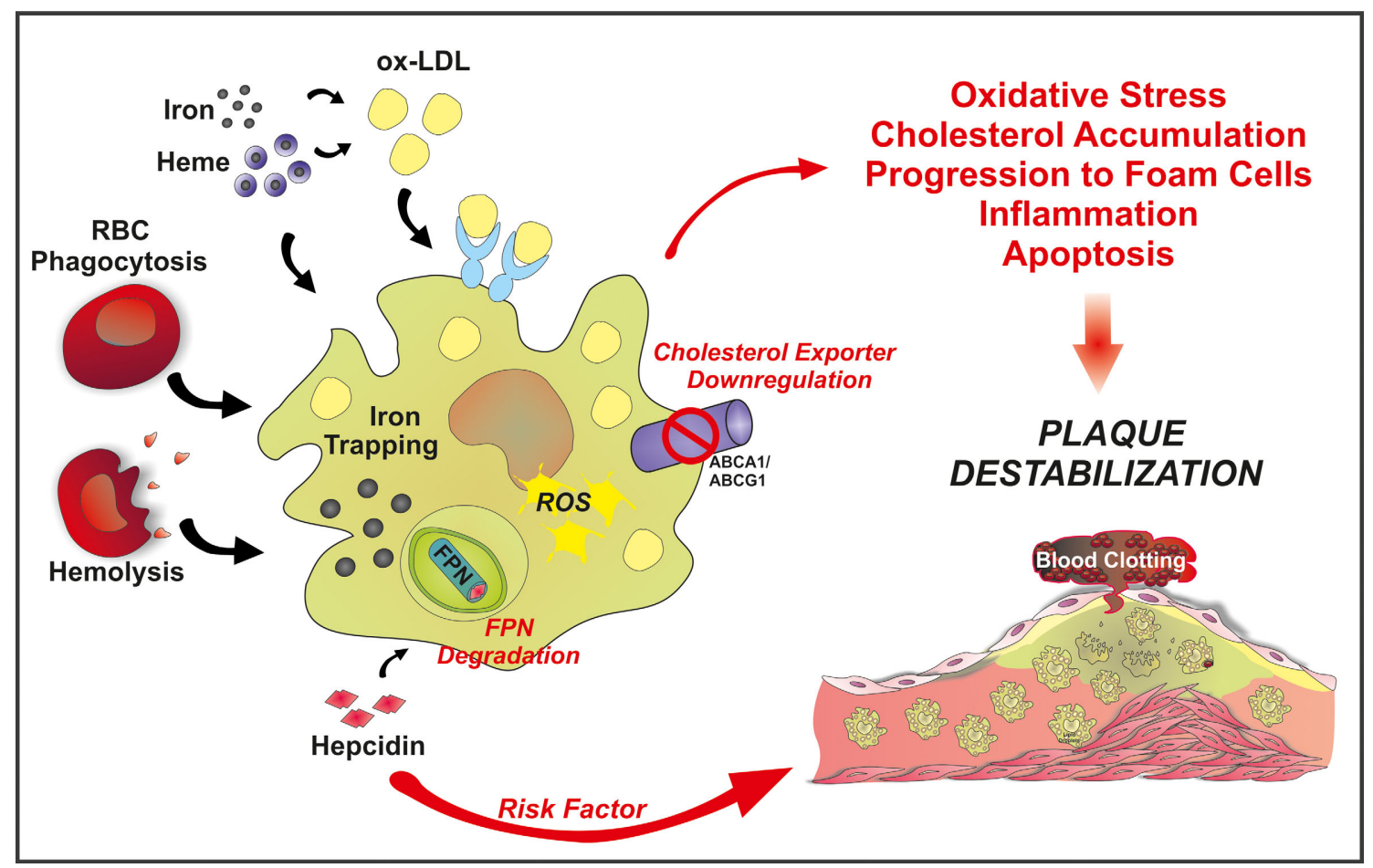

FIGURE 2 | Schematic overview of the "refined iron hypothesis": a role for macrophage-retained iron in atherosclerosis. Iron can accumulate in macrophages as inorganic iron and $\mathrm{Hb}$-iron, upon erytrophagocytosis or hemolysis. Once stored in the cell, iron can be made available to the bloodstream via FPN-mediated export. According to the refined iron hypothesis, high hepcidin levels are considered a risk factor for plaque progression and destabilization. Hepcidin is known to bind to FPN, thus promoting its degradation and blocking iron export. This increases intracellular ROS levels and decreases cholesterol efflux. As a result, the oxidative status alters and LDL accumulation occurs, promoting foam cell formation, inflammation and eventually plaque instability.
Nevertheless, different factors other than red blood cell sickling, could contribute to these events, atherosclerosis being one of this.

SCD is an uncommon risk factor for atherosclerosis. However, in the last decades, together with the increased life expectancy of SCD patients, the risk to develop atherosclerosis is significantly increasing. Endothelial dysfunction, hyperhomocysteinemia and activation of platelets are the most likely mechanisms for the development of atherosclerosis in SCD patients (Elsharawy et al., 2009). The presence of excessive circulating $\mathrm{Hb}$, heme, and iron in SCD could have in principle a crucial role in atherosclerosis development, even though a clear experimental proof of this is still missing. Conversely, a paradoxical protective effect of SCD on atherosclerosis and thrombosis was observed in ApoE-null mice transplanted with bone marrow from mice carrying the sickle cell mutation. This effect was abolished by inhibition of HO1 , suggesting that this protection relies on the activity of this enzyme, whose induction is sustained in SCD, due to the high circulating $\mathrm{Hb}$ and heme levels (Wang et al., 2013). These observations have the limit that mice were analyzed after 23-28 weeks from bone marrow transplantation, giving an idea of the onset of atherosclerosis but not of the late phases of the disease, in which HO-1 activity could be eventually overwhelmed, thus promoting atherosclerosis progression.

The most common sites of atherosclerosis in these patients are represented by large cerebral arteries (Rothman et al., 1986).
Approximately $75 \%$ of strokes in sickle cell disease are the result of occlusion of cerebral vessels (Moran et al., 1998). Also pulmonary and splenic arteries are common sites of atherosclerosis in sickle cell disease. One-third of the sickle patients had histological evidence of medial hypertrophy and intimal proliferation in these arteries (de Chadarevian et al., 2001; Graham et al., 2007).

Therefore, thalassemia and sickle cell anemia patients are considered at high atherogenic risk in view of the perturbation of the $\mathrm{Hb} /$ heme/iron metabolism that predisposes these patients to oxidative status alterations (Belcher et al., 1999; Switzer et al., 2006).

\section{HAPTOGLOBIN POLYMORPHISM AND CAD}

Extracellular $\mathrm{Hb}$ may exert proatherogenic effects via different mechanisms. Free $\mathrm{Hb}$ scavenges nitric oxide, an important vasodilator and signaling molecule (reviewed in Rother et al., 2005). Moreover, oxidized Hb species trigger pro-oxidant (reviewed in Balla et al., 2005) and pro-inflammatory effects on vascular endothelium (Silva et al., 2009), and cause lipidperoxidation (Jeney et al., 2002; Potor et al., 2013).

Efficient mechanisms have evolved to remove extracellular $\mathrm{Hb}$ from the circulation to limit its deleterious effects. Haptoglobin $(\mathrm{Hp})$ is an acute-phase plasma protein with the primary function to capture cell-free $\mathrm{Hb}$ and chaperon it to macrophages for degradation (reviewed in Alayash, 2011). Hp binding facilitates 
the removal of $\mathrm{Hb}$ from circulation via endocytosis through the CD163 macrophage scavenger receptor (Kristiansen et al., 2001).

The Hp gene is polymorphic in humans, whereby the two functional alleles (hp1 and hp2) can form three genotypes: Hp11, Hp2-1, and Hp2-2 with heterogeneous protein structure and functional differences (reviewed in Goldenstein et al., 2012). Differences between antioxidant properties of Hp1-1 and Hp2-2 were examined. An early study showed that $\mathrm{Hp} 1-1$ protein is more potent in inhibiting the oxidative actions of extracorpuscular $\mathrm{Hb}$ (Melamed-Frank et al., 2001). Contradictory, a recent study described no differences between the two phenotypes in protecting against $\mathrm{Hb}$-driven toxicity (Lipiski et al., 2013). When applied in vivo following $\mathrm{Hb}$ injection both $\mathrm{Hp} 1-1$ and $\mathrm{Hp} 2-2$ attenuate $\mathrm{Hb}$-induced blood pressure response with equal efficacy, restrict trans-endothelial diffusion of extracellular $\mathrm{Hb}$ equally, and prevent $\mathrm{Hb}$ redistribution and renal iron deposition in the same way (Lipiski et al., 2013). Both phenotypes show similar abilities to stabilize the ferryl $\mathrm{Hb}$ state, to restrict heme release from the complex, and to prevent Hb-driven LDL oxidation in vitro (Lipiski et al., 2013). Immunomodulatory effects of the two phenotypes were compared as well. The Hp1-1-Hb complex induces more robust anti-inflammatory macrophage signaling, leading to the secretion of anti-inflammatory cytokines than that of $\mathrm{Hp} 2-2-\mathrm{Hb}$ complex (Philippidis et al., 2004; Landis et al., 2013).

The Hp polymorphism was investigated as a possible genetic determinant in cardiovascular disease. These epidemiologic studies revealed that the Hp2-2 genotype is a risk factor for cardiovascular complications in both type I and type II diabetic patients (reviewed in Costacou and Levy, 2012). In particular, the Hp2-2 genotype is associated with elevated amounts of iron in atherosclerotic carotid plaques, accompanied by increased levels of oxidation-specific epitopes, increased macrophage infiltration and decreased VSMCs, all events promoting plaque instability (Lioupis et al., 2011, 2012; Purushothaman et al., 2012). In addition, the Hp2-2 genotype is associated with increased circulating oxLDL levels when compared to Hp1-1 or Hp2-1 genotypes (Brouwers et al., 2004). A correlation between the Hp22 genotype, carotid plaque instability and increased risk of major cardiovascular diseases was recently described (Ijas et al., 2013).

Collectively, these findings suggest that detoxification of extracellular $\mathrm{Hb}$ by $\mathrm{Hp}$ acts in an atheroprotective manner. In addition, the Hp2-2 genotype represents a non-modifiable risk factor for cardiovascular diseases. Because Hp1-1 and Hp2-2 inhibit the oxidative actions of extracorpuscular $\mathrm{Hb}$ equally, therefore disease association is most probably explained by other functions or properties of the Hp molecule.

\section{HEME OXYGENASE-1 (H0-1) AND CARDIOVASCULAR DISEASE}

Heme oxygenases catabolize heme to equimolar amounts of biliverdin, carbon monoxide, and free iron, followed by the conversion of biliverdin into bilirubin by biliverdin reductase (Singleton and Laster, 1965; Tenhunen et al., 1968). HO-1 is a stress-inducible isoform of heme oxygenases, encoded by the hmox-1 gene which possesses antioxidant, anti-apoptotic and anti-inflammatory properties (reviewed in Gozzelino et al., 2010; Durante, 2011). These protective mechanisms partially rely on the ability of HO-1 to extract iron from heme. The released iron induces the expression of ferritin, the 24-subunit complex of heavy $(\mathrm{H})$ and light (L) chains, with enormous iron-storage capacity (Eisenstein et al., 1991; Harrison and Arosio, 1996). In addition, both bilirubin and $\mathrm{CO}$, the other two end products of heme degradation exhibit direct anti-oxidant and antiinflammatory activities (Gozzelino et al., 2010).

An important, but somewhat neglected function of HO1 is its role in iron recycling (Poss and Tonegawa, 1997). Erythrophagocytosis, subsequent $\mathrm{HO}-1$-mediated heme degradation and iron release from macrophages is a major mechanism in iron recycling, accounting for about $90 \%$ of total body iron turnover (reviewed in Hentze et al., 2010).

Accumulating evidences suggest the protective role of $\mathrm{HO}$ 1 in atherosclerotic vascular disease (reviewed in Chan et al., 2011). Both the antioxidant bilirubin and the vasodilator CO may contribute to this atheroprotective effect (Siow et al., 1999; Mayer, 2000; Parfenova et al., 2012; Erkan et al., 2013). Low bilirubin levels are associated with endothelial dysfunction and increased intima-media thickness (Erdogan et al., 2006), whereas high plasma bilirubin concentrations are linked to low incidence of cardiovascular disease (Schwertner et al., 1994) and stroke (Kimm et al., 2009). Differences in plasma bilirubin levels may arise from the variation of HO-1 activity in humans.

In the human hmox-1 promoter a GT repeat microsatellite polymorphism exists, leading to higher hmox-1 transcriptional activity and subsequently higher $\mathrm{HO}-1$ expression in individuals having shorter GT repeats compared to subjects with longer GT repeats. A number of studies investigated the relationship between this gene polymorphism and the risk of cardiovascular disease, with conflicting results. Some studies revealed that shorter GT repeats in the hmox-1 promoter region are associated with lower incidence and/or progression of CAD (Kaneda et al., 2002; Liang et al., 2013), whereas others argue against a relevant role of this polymorphism in cardiovascular diseases (Lublinghoff et al., 2009).

Progressive atherosclerotic lesion destabilization with subsequent plaque rupture is a key event predisposing to acute thrombus formation and coronary artery occlusion (Schwartz et al., 2007). Autopsy studies reveal that the risk of plaque rupture mainly depends on the composition of the plaque rather than its size (Kolodgie et al., 2004). Severe macrophage infiltration, a necrotic core and a thin fibrous cap are the main characteristics of vulnerable plaques (Kolodgie et al., 2004). In humans, $\mathrm{HO}-1$ expression is increased in atherosclerotic lesions and closely correlates with plaque instability and pro-inflammatory markers. The observation that HO-1 induction reverses plaque progression from a vulnerable plaque to a more stable phenotype suggests that $\mathrm{HO}-1$ expression may act as a compensatory atheroprotective mechanism (Cheng et al., 2009).

By contrast, HO-1 deficiency in humans leads to severe vascular pathologies (Yachie et al., 1999). A 6-year old boy with inactivating mutations of the HO-1 gene presented with severe intravascular hemolysis associated with persistent endothelial damage. Autopsy examination revealed the presence of aortic fatty streaks and fibrous plaques at this young age, highlighting the atheroprotective function of HO-1 (Yachie et al., 1999). More recently, another case of HO-1 deficiency in a young girl 
was reported, with evidence of severe endothelial damage, as suggested by raised inflammatory markers, von Willebrand factor and coagulopathy (Radhakrishnan et al., 2011). Since free circulating heme promotes endothelial damage, the lack of functional HO-1 likely results in a form of vasculitis or endothelial injury syndrome. This may therefore increase their susceptibility to develop atherosclerosis.

Taken together, these findings prove a crucial role for HO-1 in the maintenance of vascular homeostasis and counteraction of atherosclerosis.

\section{ALTERED IRON HOMEOSTASIS AND ATHEROSCLEROSIS: ANIMAL MODELS \\ IRON OVERLOAD AND IRON DEFICIENCY IN ATHEROSCLEROSIS}

The effect of iron in atherogenesis was tested using different hypercholesterolemic animal models. In an initial study that intramuscular administration of iron dextrane augmented the formation of atherosclerotic lesions in hypercholesterolemic rabbits (Araujo et al., 1995). In contrast, another group using the same rabbit model described that iron dextrane injection significantly decreased lesion formation by about $50 \%$ by reducing plasma cholesterol levels (Dabbagh et al., 1997). Kirk et al. observed a reduction (about 50\%) in plaque area in apoE deficient mice fed with a $2 \%$ carbonyl iron containing standard diet in spite of that dietary iron overload caused a modest $(30 \%)$ rise in plasma triglyceride and cholesterol levels (Kirk et al., 2001).

Other studies took the opposite approach and examined the effect of iron restriction on atherogenesis. In this regard, atherosclerotic lesions in mice fed a low-iron diet were significantly smaller than those found in control littermates (Lee et al., 1999). Reduced plaque size in the low-iron group was associated with lower levels of circulating autoantibodies to oxLDL, and the diminished occurrence of thiobarbituric acid reactive epitopes in the lesions (Lee et al., 1999). This was explained by the observation that dietary iron restriction increases plaque stability via elevated collagen and reduces matrix metalloproteinase- 9 expressions in the lesion (Lee et al., 2003). Consistently, iron chelation by DFO lowers the iron content of the lesions and inhibits atherosclerotic lesion development in cholesterol-fed rabbit (Minqin et al., 2005) as well as in apoE deficient mice (Zhang et al., 2010). Other than an effect on atherosclerosis, several studies showed that iron depletion by chelation significantly reduces endothelial activation and vascular dysfunction in animal models (Ishizaka et al., 2005). Recently, a combined therapy of iron chelator and antioxidant was observed to restore ironinduced brain vascular dysfunction in rats (Sripetchwandee et al., 2014), supporting the idea that iron promotes earlier steps in atherogenesis.

\section{HEMOCHROMATOSIS MODELS}

Although there is support for the idea that iron is detrimental for atherosclerosis, the validity of the original iron hypothesis has not been tested in models of genetic iron overload, such as hemochromatotic mice. To date, several mouse models of hemochromatosis are available, such as HFE-null, Hamp-null, HJV-null, and BMP6-null mice (Fleming et al., 2011) but atherosclerosis progression has not been assessed in any of them. Future studies will have to dissect the contribution of systemic iron overload and macrophage iron deficiency in hemochromatotic mouse models for atherosclerosis in order to better understand the outcome of the epidemiological studies.

\section{ANIMAL MODELS TO ASSESS THE IMPACT OF MACROPHAGE IRON ON ATHEROSCLEROSIS}

The key role of macrophages in atherosclerosis was extensively studied in animal models. Lipid-laden foam cells are macrophages derived from circulating monocytes that migrate into the vessel wall. Inhibition of monocyte migration, by disrupting a variety of chemokine/chemokine receptor interactions, was shown to inhibit atherosclerosis development. The osteopetrotic (op) mouse, spontaneously deficient in macrophage-colony stimulating factor (M-CSF), displayed a reduction of $86 \%$ in plaque volume, demonstrating the essential role of macrophages in atherogenesis (Smith et al., 1995). Quite recently, a CD11bdiphtheria toxin receptor transgenic mouse line was generated, whereby diphtheria toxin administration conditionally ablates monocytes/macrophages (Stoneman et al., 2007). In atherogenesis experiments, diphtheria toxin markedly decreased monocyte numbers by $50 \%$ and altered plaque development and composition, reducing collagen content and necrotic core formation, thus demonstrating that monocytes/macrophages are critical for atherogenesis.

The crucial role of macrophages in atherosclerosis raised the possibility of selective intraplaque macrophage depletion achievable as a specific therapeutic intervention to counteract plaque progression. This approach now gains increasing attention in cardiovascular medicine. Several successful strategies have recently been reported to induce macrophage cell death in atherosclerotic plaques (Martinet and De Meyer, 2007). Its feasibility is currently debated and object of several studies, aimed at locally deleting macrophages, without affecting this cell type in other tissue compartments. However, local therapies can be administered only for a relatively short time, with the limitation that macrophages may reinfiltrate the plaque after treatment.

Assessment of the impact of macrophage-associated iron on atherosclerosis could eventually provide additional mechanisms/pathways that could be targeted in macrophages to prevent/reduce atherosclerosis. Animal studies were initiated to evaluate the role of iron in macrophages, thus revisiting the iron hypothesis. Although not tested in hemochromatotic mice, atherosclerosis was studied in mice with macrophage iron depletion triggered by drug administration. The pharmacological suppression of hepcidin in mice decreased macrophage iron content, and increased cholesterol efflux, thus resulting in reduced foam cell formation (Saeed et al., 2012). In particular, the reduction of macrophage-associated iron levels lowered the formation of ROS and increased the expression of cholesterol transporters, namely ABCA1 and ABCG1. This leads to improved lipid efflux by macrophages, correlating with reduced foam cell formation and atherosclerosis (Figure 2). This approach is limited by the use of a BMP signaling pathway inhibitor to achieve hepcidin suppression. BMP signaling inhibitors are in fact expected to effect on many other biological processes involved in the formation of the atherosclerotic plaque, other than those directly dependent on 
hepcidin reduction. Future studies that apply drugs that directly and specifically reduce hepcidin expression or that counteract its activity are needed to examine whether hepcidin suppression by itself affects progression of atherosclerosis.

In agreement with these findings, hepcidin recently emerged as a positive regulator of atherosclerotic plaque destabilization, via regulating macrophage iron homeostasis (Li et al., 2012). Hepcidin production in the carotid artery was achieved by adenoviral infection in a mouse model of accelerated atherosclerosis. Although a change in plaque size was not observed, hepcidin overexpression significantly affected plaque composition, increasing intraplaque macrophages and decreasing VSMCs and collagen amounts. Additionally, hepcidin overexpression increased trapped iron as well as oxidized-LDL levels in intraplaque macrophages. This correlated with increased oxidative stress and expression of pro-inflammatory cytokines by macrophages and enhanced plaque vulnerability, suggesting that hepcidin plays a critical role in plaque destabilization.

Collectively, these findings indicate that the interactions of hepcidin, trapped iron, and accumulated lipids are critical for proatherosclerotic activation of macrophages leading to plaque destabilization (Figure 2). The suppression of hepcidin by specific shRNA exerts effects opposite to those reported above. These studies described a unique role for hepcidin in promoting atherosclerosis progression and plaque instability and provided evidence of a protective function of the iron-spared macrophage, at least partially clarifying the paradoxical issues observed in hemochromatosis.

A complementary approach to test the effect of iron-loaded macrophages on atherosclerosis was recently pursued (Kautz et al., 2013). Atherosclerosis was studied in the flatiron (ffe) mouse (Zohn et al., 2007), a model that specifically accumulates iron in macrophages. Contrary to the refined iron hypothesis, atherosclerosis was not increased in mice with elevated macrophage iron. In addition, increased macrophage iron levels triggered by parenteral iron administration also failed to promote atherosclerosis. These findings dispute that macrophage iron loading could be an aggravating factor in the pathogenesis of atherosclerosis.

\section{EFFECTS OF HO-1 IN ANIMAL MODELS OF ATHEROSCLEROSIS}

The role of HO-1 in atherosclerotic lesion formation was first investigated in apoE deficient mice, overexpressing $\mathrm{HO}-1$. Overexpression of HO- 1 in the vasculature was achieved by direct injection of an adenovirus expressing HO-1 (Adv-HO-1) into the left ventricles of anesthetized animals. HO-1 overexpression inhibits lesion formation and reduces iron overload in apoE deficient mice (Juan et al., 2001). Reduced iron deposition in aortic tissues of Adv-HO-1-treated mice might be explained by the observation that HO-1 overexpression augments iron recycling from cells (Ferris et al., 1999). To further examine the role of HO- 1 in atherogenesis, mice deficient in both HO-1 and apoE were generated. When compared to apoE deficient mice these double knock-out mice exhibited accelerated and more advanced lesion formation in response to a cholesterol rich diet (Yet et al., 2003). Interestingly, aged HO-1 knock-out mice exhibit severe aortitis and coronary arteritis with mononuclear cell infiltration accompanied by fatty streak formation, even on a standard chow diet (Ishikawa et al., 2012).

Expression of HO-1 is strongly regulated by its substrate heme, in a Bach1-mediated manner. Bach1 is a transcriptional repressor of the hmox-1 gene that becomes inactive and undergoes ubiqitination and degradation upon heme binding (Zenke-Kawasaki et al., 2007). Consequently, deletion of the bach1 gene leads to sustained HO-1 expression in various tissues. The effect of bach 1 deletion in atherosclerosis was studied in Bach1 apoE double deficient mice (Watari et al., 2008). In these mice HO-1 was upregulated in the vasculature, mainly in the vascular endothelium (Watari et al., 2008). Elevated HO-1 expression was accompanied by reduced plaque area compared with that in apoE deficient mice, supporting the anti-atherogenic nature of HO-1 (Watari et al., 2008). Overexpression of HO-1 inhibited lesion progression into vulnerable plaques, whereas inhibition of $\mathrm{HO}-1$ activity augmented plaque vulnerability (Cheng et al., 2009).

Biological effects of a wide variety of molecules depend on the upregulation of HO-1 by these compounds (Bach, 2005). Accordingly, there are several anti-atherosclerotic compounds that exert their protective effects via the induction of HO-1. For example the anti-oxidant probucol, has been shown to protect from atherosclerosis by a HO-1 pathway that is independent of radical scavenging in various models of vascular diseases $(\mathrm{Wu}$ et al., 2006). Recently, HO-1 was found to be the molecular target of Tanshinone IIA, a lipophilic bioactive compound extracted from Salvia miltiorrhiza Bunge that exert anti-atherogenic effect via suppressing cholesterol accumulation in macrophages (Liu et al., 2014). In addition, the polyphenolic compound quercetin as well attenuates endothelial dysfunction and atherosclerosis in apoE deficient mice in a HO-1 dependent manner (Shen et al., 2013).

Taken together, these results support a protective function for $\mathrm{HO}-1$ in atherosclerotic lesion formation and progression.

\section{EFFECT OF IRON ON MAIN PLAYERS IN ATHEROGENESIS LIPID METABOLISM AND LDL OXIDATION}

Elevated iron stores reflected by increased plasma ferritin levels are positively correlated with the prevalence of certain diseases such as metabolic syndrome, diabetes and obesity (Jehn et al., 2004, 2007; Lecube et al., 2008; Sun et al., 2008). All of these diseases are associated with abnormal lipid metabolism, but until recently there were few studies addressing whether elevated iron levels and lipid metabolism are directly correlated. A first study showed that $\mathrm{HH}$ associated with primary hypertriglyceridemia (Solanas-Barca et al., 2009), which can be improved by periodic therapeutic phlebotomy (Casanova-Esteban et al., 2011). In rats with dietary iron overload a significant increase in triglycerides, free cholesterol, cholesteryl ester, and high-density lipoproteincholesterol levels was observed (Brunet et al., 1999). By contrast, intraperitoneal injection of iron-dextrane enhanced serum triglyceride levels but not serum cholesterol levels in an independent study (Silva et al., 2008). Excess iron directly modulates activities of several key enzymes for cholesterol and triglyceride homeostasis-e.g., 3-hydroxy-3-methylglutaryl coenzyme A reductase, cholesterol 7alpha-hydroxylase, acyl-CoA: cholesterol acyltransferase and lipoprotein lipase - which might explain 
perturbations of lipid metabolism in conditions of iron overload (Brunet et al., 1999).

Other than affecting lipid metabolism, iron mediates the oxidative modification of LDL, a clear contributing factor to the pathogenesis of atherosclerosis (Heinecke et al., 1984). The molecular mechanism of iron-catalyzed LDL oxidation was extensively studied. Redox active iron that undergoes oxidation and reduction is an absolute necessity to catalyze lipid peroxidation (Lynch and Frei, 1993; Miller et al., 1993). Iron-mediated oxidation of LDL is dependent on superoxide anion $\left(\mathrm{O}_{2}^{-\bullet}\right)$ that acts as a $\mathrm{Fe}^{3+}$ reducing agent, but requires neither $\mathrm{H}_{2} \mathrm{O}_{2}$ nor production of hydroxyl radical $\left(\mathrm{OH}^{\bullet}\right)$ by the Fenton reaction (Lynch and Frei, 1993).

The unlikely existence of iron in free catalytically active form in normal body fluids initiated the search for physiologically more relevant iron compounds with the ability to oxidize LDL. In fact most of the iron in the human body is found in heme that serves as a prosthetic group in $\mathrm{Hb}$ and other heme proteins. This ubiquitous iron compound is a very efficient catalyst of LDL oxidation (Balla et al., 1991a). Studies revealed that initiation and propagation of heme-induced lipid-peroxidation is independent of Fenton chemistry similarly to that of iron-mediated LDL oxidation. The initial interaction between heme and $\mathrm{H}_{2} \mathrm{O}_{2}$ might lead to the formation of ferryl and perferryl radicals, those can be responsible for initiating lipid peroxidation (Klouche et al., 2004). During heme-mediated LDL oxidation, oxidative scission of the heme ring occurs and iron is released (Balla et al., 1991a). Both heme degradation and LDL oxidation are effectively inhibited by lipid soluble antioxidants and iron chelators (Balla et al., 1991a; Pocsi et al., 2008).

Several lines of evidence suggest that heme-mediated oxidation of LDL occurs in vivo. High amount of heme in the plasma of the HO-1 deficient boy was correlated with extensive LDL oxidation (Jeney et al., 2002). During heme-mediated LDL oxidation heme reacts with proline and arginine residues in apolipoprotein B-100 and a unique oxidation product, gammaglutamyl semialdehyde is formed, that is subsequently reduced to 5-hydroxy-2-aminovaleric acid (HAVA). HAVA is a hallmark of heme-mediated LDL oxidation, as other agents known to trigger LDL oxidation, such as $\mathrm{HOCl}, \mathrm{H}_{2} \mathrm{O}_{2}$ alone or in combination with $\mathrm{Cu}^{2+}$ or $\mathrm{Fe}^{2+}$ induce only minor HAVA formation (Julius and Pietzsch, 2005). Elevated concentrations of HAVA were found in LDL of patients with impaired glucose tolerance and with diabetes mellitus suggesting that heme-mediated LDL oxidation occurs in these patients (Julius and Pietzsch, 2005).

Cell-free $\mathrm{Hb}$ when oxidized releases heme and induces oxidative modification of LDL (Jeney et al., 2002). This effect was abolished by the heme-scavenging protein $\mathrm{Hx}$ and by $\mathrm{Hp}$ or cyanide, agents that either bind free heme or strengthen the heme-globin bond, highlighting the role of heme release in this process (Miller et al., 1996; Jeney et al., 2002). Recently a feedforward process in atheromatous lesions with the interactions of atheroma lipids and cell free $\mathrm{Hb}$ was described. This vicious cycle includes lipid-hydroperoxide mediated oxidation of $\mathrm{Hb}$, spontaneous heme release, oxidative heme scission, iron release, and further lipid peroxidation (Nagy et al., 2010; Jeney et al., 2013; Potor et al., 2013).
Collectively, these results confirm that excess iron, heme, and cell-free $\mathrm{Hb}$ act in an atherogenic manner.

\section{ENDOTHELIAL CELL ACTIVATION AND DYSFUNCTION}

Upon steady-state condition, endothelial cells provide an antithrombotic and antiadhesive surface in the vasculature. Lowgrade inflammation is a characteristic of the atherosclerotic lesions in which endothelial cell activation occurs, triggering vasoconstriction, thrombosis as well as leukocyte adhesion, and transmigration (Libby, 2002). This pro-inflammatory response relies on the upregulation of a variety of genes encoding vasoconstrictive, pro-thrombic, pro-inflammatory, chemotactic, and adhesive molecules (reviewed in Pober and Sessa, 2007). Redoxsensitive mechanisms involving the activation of redox-regulated transcription factor nuclear factor-kB (NF-kB) have been implicated in the expression of these vascular inflammatory molecules (Marui et al., 1993; Kunsch and Medford, 1999).

Accumulating evidences suggest the critical role of redox active iron in mediating the pro-inflammatory response in endothelial cells. Chelation of iron by DFO leads to decreased induction of E-selectin, vascular cell adhesion molecule-1 (VCAM-1), and intercellular adhesion molecule-1 (ICAM-1) in endothelial cells stimulated by tumor necrosis factor alpha (TNF alpha) (Zhang and Frei, 2003). Switching to in vivo models, iron chelation inhibits the lipopolysaccharide-mediated induction of soluble cellular adhesion molecules, monocyte chemoattractant protein1 (MCP-1) and activation of NF-kB in mice (Zhang et al., 2010). In humans, iron chelation by DFO improves nitric oxidemediated endothelium-dependent vasodilation in patients with $\mathrm{CAD}$, highlighting a role for iron in impaired nitric oxide action in atherosclerosis (Duffy et al., 2001).

The direct association between excess iron and endothelial dysfunction has been established upon physiological and pathological conditions. Administration of iron into healthy individuals provoked endothelial dysfunction accompanied by increased generation of superoxide radical in whole blood (Rooyakkers et al., 2002). Hemodialysis (HD) patients who receive intravascular iron along with erythropoiesis-stimulating agents to treat functional iron deficiency and subsequent anemia, as well as iron-overload patients, provide a unique opportunity to study the effect of iron on vascular function. There are conflicting data regarding the effect of iron on vascular function, cardiovascular risk and overall mortality in HD patients. Serum ferritin was reported as a marker of mortality in HD patients, but whether ferritin levels were regulated by iron in these patients is not clear (KalantarZadeh et al., 2001). High serum ferritin level in HD patients $(>600 \mu \mathrm{g} / \mathrm{L})$ is associated with increased overall 4 -year mortality even in the absence of infection (Kletzmayr and Horl, 2002). A cohort study concluded that iron supplementation at a dose of $1000 \mathrm{mg}$ or less over 6 month does not have any adverse effect, whereas iron supplementation at higher doses is associated with elevated morbidity (Feldman et al., 2004).

Recently, more mechanistic studies were performed to show the involvement of endothelial dysfunction in iron-triggered cardiovascular complications. Intravenous administration of iron increased the levels of circulating soluble adhesion molecules in HD patients which was associated with higher risks for 
cardiovascular events (Kuo et al., 2012). Consistently, endothelial cells treated with iron sucrose, a widely used iron drug, changed their morphology and showed an increased ability to recruit monocyte (Kamanna et al., 2012). Iron sucrose treatment causes marked reduction in acetylcholine-mediated relaxation in rat aorta rings, thus further confirming the detrimental effect of iron on endothelial function (Kamanna et al., 2012). Iron overload diseases are associated with the presence of NTBI in the serum. In serum from hemochromatosis patients, NTBI levels were found to be positively correlated with the expressions of adhesion molecules, ICAM-1, VCAM-1, and E-selectin but not to the inflammatory marker CRP (Kartikasari et al., 2006).

Hemolytic diseases are also associated with endothelial dysfunction, therefore several studies addressed whether cell free $\mathrm{Hb}$ or heme can harm endothelial cells directly in these pathologies. Heme strongly sensitizes endothelial cells to oxidant-mediated killing and its plasma scavenger, $\mathrm{Hx}$, completely inhibits this effect (Balla et al., 1991b). Hb when oxidized to metHb can transfer heme to the endothelium and exert the same sensitizing effect as free heme (Balla et al., 1993). More recently globinglobin cross-linked $\mathrm{Hb}$ multimers were identified in complicated atherosclerotic lesions (Nagy et al., 2010). The formation of these species can be triggered by inorganic and organic peroxides and involves the generation of ferrylHb and globin radicals (reviewed in Jeney et al., 2013). Interestingly, these globin-globin cross-linked $\mathrm{Hb}$ multimers are the exclusive species inducing pro-inflammatory response in endothelial cells in vitro. As a pro-inflammatory agonist, globin-globin cross-linked $\mathrm{Hb}$ multimers trigger the formation of intercellular gaps disrupting the integrity of the endothelial cell monolayer, induce the expression of adhesion molecules, E-selectin, ICAM-1, and VCAM-1 leading to increased monocyte adhesion (Silva et al., 2009; Potor et al., 2013).

Recently, the study of mouse models of hemolytic diseases ( $\beta$-thalassemia and sickle cell disease mice) proved that heme largely contributes to endothelial activation and dysfunction and cardiovascular alterations (Tolosano et al., 2010; Vinchi and Tolosano, 2013). These effects can be strongly counteracted by the administration of an Hx-based therapy (Vinchi et al., 2008, 2013). Most of these effects have been described to rely on heme ability to activate TLR4 in endothelial cells. Heme-mediated TLR4 activation leads to Weibel-Palade body (WPB) mobilization and degranulation, thus promoting the expression of P-selectin and VWF, and NF- $\kappa \mathrm{B}$ activation in endothelial cells in vitro and vessel wall surfaces in vivo (Belcher et al., 2014). By activating TLR4 pathway, heme triggers vascular stasis and occlusion, common complications associated with hemolytic disorders such as sickle cell disease. TLR4-null mice transplanted with sickle bone marrow do not exhibit heme-induced vaso-occlusion and activation of WPB/NF- $\mathrm{BB}$. The ability of $\mathrm{Hb}$ and heme to induce stasis is abolished by the administration of the $\mathrm{Hb}$ and heme scavengers, $\mathrm{Hp}$ and Hx in a mouse model of SCD (Belcher et al., 2014). In addition heme has been recently described as a trigger of the acute chest syndrome, one of the major complications associated with SCD. In a sickle mouse model, respiratory failure due to ACS was avoided by treatment with recombinant $\mathrm{Hx}$. The activation of TLR4 by heme in vascular tissues was likely responsible for this lethal type of acute lung injury. Pharmacologic inhibition of TLR4 protected sickle mice from heme-induced ACS (Ghosh et al., 2013).

These recent findings highlight a crucial role for the TLR4activated signaling pathway in $\mathrm{Hb}$ /heme-mediated activation of endothelial cells and macrophages. From the point of view of atherosclerosis, a role for TLR4 in the initiation and progression of the disease is widely recognized. TLR4 is expressed on the cell surface of the main cell types involved in atherosclerosis, endothelial cells, platelets and macrophages. Its activation is required to enhance the expression of adhesion molecules and cytokines (e.g., MCP1), thus promoting the recruitment of monocytes and initiating the inflammatory response. The enhanced cytokine and chemokine release by TLR4 activation could stimulate EC and VSMC migration and proliferation, thus accelerating plaque progression (Pasterkamp et al., 2004). Additionally, oxLDL upregulate TLR4 expression and induce cytokine expression at least partially via TLR4 activation (Pasterkamp et al., 2004; den Dekker et al., 2010). Also platelets participate in atherogenesis and show clear signs of increased activity in individuals with established cardiovascular and thrombotic disease. Increased activation of platelets via TLR4 binding could increase the risk of atherosclerosis and thrombosis (Jayachandran et al., 2010) and heme could potentially promote this event. Some mouse models and human studies also support a role of TLR4 in the progression of atherosclerotic disease. Individuals with TLR4 deficiency may be at increased risk for infection but at lower risk for cardiovascular disease (Jayachandran et al., 2010). Besides heme scavenging by $\mathrm{Hp}$ and $\mathrm{Hx}$, targeting TLR4 as a signaling receptor downstream of heme could be an alternative therapeutic approach to reduce heme-driven pro-atherogenic effects.

Heme and oxidized $\mathrm{Hb}$ species can also threaten vascular endothelial cell integrity indirectly by their ability to mediate the oxidative modification of LDL (reviewed in Balla et al., 2005). Lipid hydroperoxides are transiently formed during LDL oxidation and responsible mostly for oxLDL-mediated endothelial damage and for initiation of redox signaling (Nagy et al., 2005, reviewed in Chapple et al., 2013).

Altogether these finding indicate that excess iron, extracellular $\mathrm{Hb}$ and heme have detrimental effects on the vascular endothelium leading to endothelial dysfunction.

\section{THE EFFECT OF IRON ON MACROPHAGE POLARIZATION AND FUNCTION}

During atherogenesis, blood monocytes are recruited to the vascular endothelium and attracted to the subendothelial space where the deposition of LDL occurs. These monocytes are later differentiated into macrophages and foam cells. Atherosclerosis macrophages are one of the most important cell populations, as they contribute to the progression of the lesions.

Macrophages are innate immune system cells therefore they exhibit great plasticity. Different stimuli and environments can lead to diverse phenotypes. Their functions comprise inflammatory responses, antimicrobial activity, tissue remodeling and iron recycling (Khallou-Laschet et al., 2010; Leitinger and Schulman, 2013). 
Macrophages are key players in the regulation of iron homeostasis as they recycle 20-25 mg of iron per day from senescent erythrocytes. Macrophages engulf aged or damaged erythrocytes and catabolize heme via HO-1 activity. Heme-derived iron is then exported from phagocytic vesicles by the natural resistanceassociated macrophage protein 1 (NRAMP1) and divalent metal transporter 1 (DMT1) expressed within phagolysosomal membranes. Iron is either stored coupled to ferritin or exported as ferrous iron via FPN, the only known iron exporter (Hentze et al., 2010). Interestingly, several studies demonstrated that much of the iron within plaques is associated with macrophages and foam cells. The exact source of iron still needs to be elucidated. However, it is well known that an important contribution is made by $\mathrm{Hb}$-contained iron that is released from microhemorrhage within the plaque (Boyle et al., 2009; Saeed et al., 2012).

The identification of different macrophage subtypes that polarize in response to a specific microenvironment (Leitinger and Schulman, 2013), in both human and murine atherosclerotic lesions, raised the possibility that iron itself could affect macrophage plasticity. A putative involvement of iron in the polarization of some macrophage subtypes has been recently demonstrated in atherosclerosis (Figure 3).

Two major subtypes of macrophages have been extensively studied and described: the classical activation (M1) and the alternative activation (M2) macrophages (Figure 3). M1 macrophages are polarized after exposure to IFN $\gamma$ and/or microbial products such as LPS. These macrophages are characterized by a strong pro-inflammatory activity with the production of several inflammatory cytokines: IL-1 $\beta$, IL-6, IL-8, IL-12, and TNFo (Butcher and Galkina, 2012). In terms of iron metabolism, M1 macrophages are prone to a low turn-over of iron with low expression of CD163, HO-1, FPN and high expression of ferritin, suggesting an iron retention phenotype with decreased iron recycling and export capacity (Recalcati et al., 2010). In chronic venous leg ulcers and wound healing models, macrophage iron overload induces an unrestrained pro-inflammatory M1 phenotype, via enhanced production of $\mathrm{TNF} \alpha$ and hydroxyl radicals, suggesting that iron accumulation in macrophages contributes to a pro-inflammatory phenotype (Sindrilaru et al., 2011). Similarly, macrophage exposure to heme could lead to a pro-inflammatory activation of these cells. In fact, heme has been described as an extracellular signaling molecule able to affect the innate immune response thanks to its ability to bind and activate TLR4. By activating TLR4 heme, induces the secretion of (TNF-alpha) by macrophages (Figueiredo et al., 2007), suggesting that heme retains the ability to polarize macrophages toward an M1 rather an M2 phenotype. Whether plaque-associated macrophages are polarized toward the M1 or M2 phenotype in hemolytic sickle animal models or patients still needs to be investigated to address this point.

In atherosclerosis M1 macrophages were detected in both human and mouse lesions, in the lipid core of the plaque. M1 macrophages were the prevalent macrophage subtype in advanced lesions (Khallou-Laschet et al., 2010). It is postulated that M1 macrophages might contribute to the formation of the necrotic core, since inflammatory macrophages are prone to

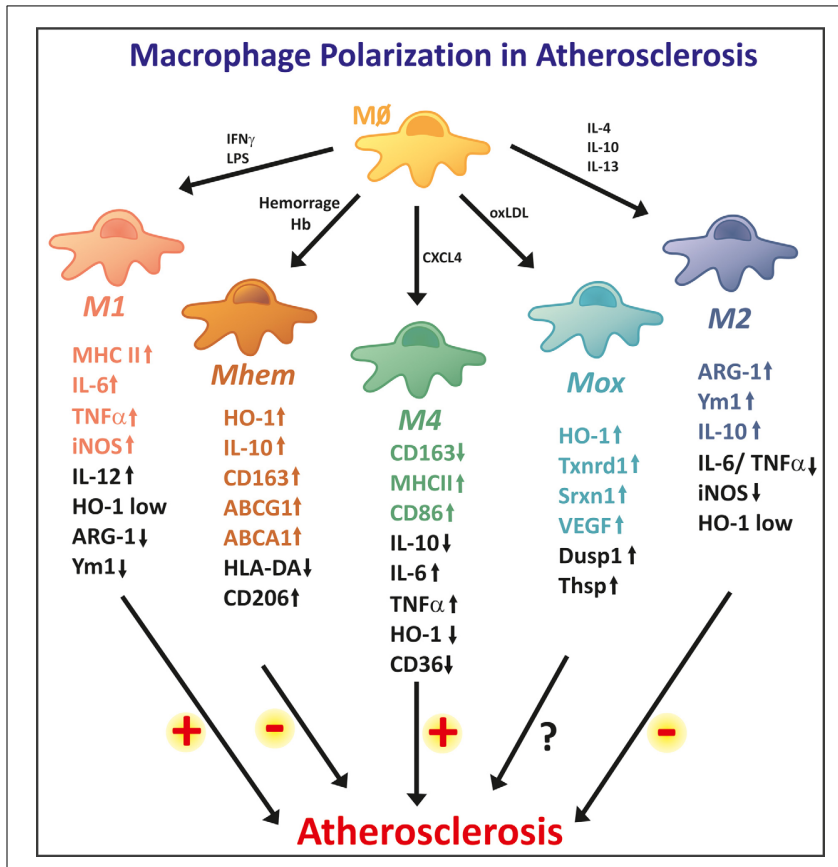

FIGURE 3 | High macrophage plasticity in atherosclerosis. In the atherosclerotic plaque, macrophages differentiate into different phenotypes. The two extreme phenotypes are represented by $\mathrm{M} 1$ and $\mathrm{M} 2$ macrophages. M1 macrophages show strong pro-inflammatory properties, thus potentially being involved in lesion progression. M1 macrophages show high expression levels of iNOS, MHCIl, and inflammatory cytokines, such as IL-6 and TNF-a. M2 macrophages are considered anti-inflammatory and are involved in tissue repair and remodeling. M2 specific markers are Arginase 1, Ym1, and IL-10. The M2 phenotype is reported as anti-atherogenic. In addition, several other macrophage phenotypes are observed in the atherosclerotic plaque. Mhem macrophages originate as a consequence of intraplaque hemorrhage and are endowed with high $\mathrm{Hb}$ handling ability. These anti-atherogenic macrophages express high levels of the heme-degrading enzyme $\mathrm{HO}-1$ and the $\mathrm{Hp}-\mathrm{Hb}$ scavenger receptor CD163. Additionally, Mheme macrophages express the cholesterol exporters $A B C A 1$ and $A B C G 1$, thus efficiently activating reverse cholesterol efflux. Mox macrophages are generated upon oxidized phospholipid stimulation. They show anti-oxidant properties, as they express genes involved in the anti-oxidant responses such as HO-1, Txnrd1, and Srxn1. Their potentially athero-protective effect still needs to be demonstrated. M4 macrophages differentiate in response to the chemo-attractant CXCL4, thus showing pro-inflammatory and pro-atherogenic effects. These macrophages express low levels of CD163 and high levels of $\mathrm{MHCII}$ and CD86. M1 and M4 macrophages promote, while M2 and Mhem macrophages counteract foam cell formation, thus having opposite effect on atherosclerosis progression.

evolve in foam cells, eventually leading to apoptosis and cell content release. Moreover, the release of TNF $\alpha$, IL-1 $\beta$, IL- 6 and other inflammatory cytokines by M1 macrophages in the lesion environment may contribute to the activation of endothelial cells (increasing the expression of LFA-1, VCAM-1, ICAM-1, CCL2, CD62P, and CD62E) and smooth muscle cells (increasing the expression of CCL2, CCL9, CX3CL1, CXCL10, CXCL16, and VCAM-1) and an overall increase in oxidative stress by the production of reactive oxygen and nitrogen species. In addition, M1 macrophages are associated with the response of Th1 lymphocytes, which is in accordance to an increased inflammatory 
response (Butcher and Galkina, 2012). All these events are expected to promote atherosclerotic plaque progression.

The alternative M2 macrophages are polarized after exposure to IL-4 or IL-13 and display an anti-inflammatory phenotype. M2-like macrophages have been described in wound healing as well as in association with tumors and with human carotid atherosclerotic plaques (Bouhlel et al., 2007). This subtype of macrophages has enhanced capacity for phagocytosis, tissue remodeling and matrix metalloproteases production (Martinez et al., 2006; Mosser and Edwards, 2008). In contrast to M1, M2 macrophages have higher expression of CD163, HO-1 and FPN and low expression of ferritin, suggesting that these macrophages have an iron release phenotype with increased iron uptake, recycling and export but low iron retention (Recalcati et al., 2010; Cairo et al., 2011). In atherosclerosis, M2 macrophages are mainly found in early lesions and are characterized by the expression of CD68 and mannose receptor (Chinetti-Gbaguidi et al., 2011). They preferentially localize in the area of the plaque overlying the lipid core (Khallou-Laschet et al., 2010). M2 macrophages are less susceptible to become foam cells and they also display a lower ability to handle lipids and to export cholesterol, due to the downregulation of the cholesterol exporter ABCA1 and the LDL carrier apoE. Also upregulation of genes involved in phagocytosis suggests that M2 macrophages in atherosclerosis have an enhanced phagocytic activity by clearing up cellular debris and dead cells (Chinetti-Gbaguidi et al., 2011). M2 macrophages are associated with a Th2 type response (Butcher and Galkina, 2012). These macrophages do not contribute to the activation of endothelial cells or smooth muscle cells since they have anti-inflammatory properties (Kleemann et al., 2008). Altogether-less susceptibility to become foam cells, high phagocytic activity and antiinflammatory properties - place these macrophages as protective for the atherosclerotic lesion development.

Recently, new subtypes of macrophages have been described in the context of atherosclerosis, supporting the idea of an increasing diversity of macrophage subsets within the lesions.

The platelet-derived chemokine CXCL4 promotes the differentiation of monocytes to macrophages toward an M4 macrophage subtype (Gleissner et al., 2010b) (Figure 3). There is no doubt that CXCL4 is important for atherosclerosis since the deletion of the PF4 gene that encodes CXCL4 reduces atherosclerotic lesions in apoE deficient mice (Sachais et al., 2007). M4 macrophages display a distinct transcriptome when compared to M1 and M2 macrophages. The major characteristic of this subtype relies on the downregulation of CD163, the Hp-Hb scavenger receptor, which indicates that M4 macrophages are not able to clear Hb after plaque hemorrhage (Gleissner et al., 2010a,b). The incapacity of $\mathrm{Hb}$ uptake is consistent with the absence of HO-1 upregulation which has a protective and anti-inflammatory effect in atherosclerotic lesion (Gleissner, 2012). This also might have some implication for iron handling but further studies are necessary to characterize this macrophage subtype regarding iron turnover. In addition M4 macrophages showed reduced expression of cholesterol scavenger receptors, leading to a decreased ability to clear modified LDL. Immunohistochemistry of human post-mortem coronary arteries revealed the presence of CD68+ CD163+ as well as CD68+ CD163 - macrophages, showing a correlation in the expression levels of CD163 and CXCL4 (Gleissner et al., 2010a). Whether this macrophage subtype promotes or protects against atherosclerotic plaque progression still needs to be addressed. On the basis of their reduced $\mathrm{Hb}$ clearance ability, a detrimental role of M4 macrophages in atherosclerosis could be speculated. Future research will be required to establish whether M4 macrophages represent a promising therapeutic target in human atherosclerosis.

Atherosclerotic lesions are characterized by the accumulation of oxidized phospholipids that also play a role in macrophage polarization. A novel macrophage phenotype denominated Mox macrophages was identified in the lesions of mice deficient for the LDL receptor (Kadl et al., 2010) (Figure 3). Mox macrophages were identified in atherosclerotic plaques in mice and accounted for $30 \%$ of all CD11b+/F4/80+ cells in established lesions. In vitro treatment of bone marrow-derived macrophages (BMDMs) with oxidized phospholipids reproduced differentiation toward this macrophage subtype that is distinct from both M1 and M2 subtypes. Considering the pro-oxidant action of iron, increased iron levels would be expected to enhance lipid oxidation, thus promoting Mox polarization. Whether this occurs in conditions of body iron overload has not been demonstrated.

Mox macrophages show a characteristic expression profile, including the upregulation of HO-1, thioredoxin reductase 1 and sufiredoxin-1, whose expression is dependent on the redoxsensitive transcription factor Nrf2 (Kadl et al., 2010; Butcher and Galkina, 2012). These Mox-specific genes may have important functions in controlling oxidative status in an oxidizing environment and protecting cells from dying in oxidatively damaged tissue. It was demonstrated that failure of $\mathrm{Nrf} 2$ expression leads to various diseases related to oxidative stress, inflammation, and xenobiotic metabolism in mice. Based on these findings, a protective role of Nrf2-driven Mox macrophages in atherogenesis would be expected. Surprisingly, a recent study showed that Nrf2-null mice were protected against diet-induced atherosclerosis. Whether these Nrf2-driven Mox macrophages contribute to the initiation or progression of atherosclerotic lesion formation remains to be investigated.

Intraplaque hemorrhage is one of the key events in advanced atherosclerotic lesions leading to iron accumulation and increased oxidative stress, thus contributing to lesion development. Erythrophagocytosis is an important source of iron in plaqueassociated macrophages and increased ferritin correlates with macrophage infiltration in human atheroma (Yuan et al., 1996). The recent description of hemorrhage-associated macrophages in atherosclerotic lesions further confirmed that hemorrhagederived $\mathrm{Hb}$ is a source of iron for intraplaque macrophages and directs their polarization into a specialized phenotype, able to handle high Hb/iron amount (Boyle et al., 2009; Finn et al., 2012). These macrophages show high $\mathrm{Hb}$ handling capacity and antiatherogenic properties and were named Hemorrhage-associated macrophages (HA-mac), Hb-stimulated macrophages, $\mathrm{M}(\mathrm{Hb})$ or heme-directed macrophages (M-hem) (Figure 3).

Macrophages associated with hemorrhage areas were characterized as CD163 high and HLA-DRlow (Boyle et al., 2011b). Moreover, as a consequence of enhanced Hb clearance, HA-mac macrophages have increased HO-1 and FPN expression, leading 
to facilitated heme catabolism and reduced intracellular free iron. Thus, they show antioxidative characteristics, increased expression of cholesterol exporters and resist foam cell formation both in vivo and in response to cholesterol loading. The reduction in intracellular free iron available for ROS formation causes increased expression of cholesterol exporters, via the activation of the LXRs (liver X receptors) pathways. HA-mac macrophages are distinct from the macrophages found in the lipid core and seem to play an atheroprotective role. In vitro stimulation of monocytes with $\mathrm{Hb}-\mathrm{Hp}$ complexes showed a differentiation toward an HAmac phenotype, suggesting that $\mathrm{Hb}$ released upon hemorrhage might model monocytes recruited to the lesion toward a specific HA-mac subtype (Boyle et al., 2011b). After treatment of human blood monocytes with heme HO-1and CD163 are upregulated, a process depending onNrf2 and the activating transcription factor 1 (Boyle et al., 2011a). Altogether, these findings suggest that ironspared macrophages may have a protective role, as postulated by Sullivan, and that the pharmacological manipulation of iron homeostasis may be a promising target to increase macrophage reverse cholesterol transport, thus limiting atherosclerosis.

Mhem macrophages exemplify how iron can affect macrophage differentiation and function, in such a way that they can handle large amounts of $\mathrm{Hb}$ and iron, thus limiting ironmediated oxidative effects and preventing lesion progression.

In atherosclerosis, macrophage activity and iron metabolism might be intrinsically connected. It is interesting to note that macrophage polarization is driven according to the specific microenvironment of the atherosclerotic lesion. The description of the different macrophage subtypes reported above suggests that also iron, in the form of $\mathrm{Hb}$ or via LDL oxidation, can differentially affect macrophage polarization. How broad is the range of macrophage subtypes generated in response to iron and how these subtypes contribute to atherosclerosis progression is not clear yet. Further studies are required to estimate the contribution of different iron sources to macrophage polarization and their impact on the atherosclerosis process.

\section{THE EFFECT OF IRON ON VSMC PHENOTYPE SWITCH}

VSMC are the predominant cell type of the medial layer of the vessel wall. Under physiological conditions, VSMC show high contractility and a low proliferation rate. These properties are essential for VSMC to perform its primary function, contraction and dilatation of vessels to regulate blood pressure and flow. However, VSMC are not terminally differentiated cells but show the capacity to switch to synthetic, inflammatory, osteochondrogenic or macrophage-like, phenotypes upon certain stimuli. The synthetic phenotype is characterized by loss of contractility, increased motility and high proliferation rate (Campbell and Campbell, 1985). Synthetic VSMC are involved in fibrous cap formation during atherogenesis. Inflammatory VSMC phenotype is defined by cytokine secretion (e.g., IL-8, IL-6) and cell adhesion molecule expression (e.g., VCAM-1), that can regulate monocyte/macrophage adhesion and recruitment (Orr et al., 2010). Under certain pathological condition, VSMCs can undergo phenotypic transition into osteoblastlike cells, whereby they synthesize excessive extracellular matrix with parallel loss of their original function (Jono et al., 2000;
Giachelli et al., 2001; Giachelli, 2003), reviewed in Sallam et al. (2013). Osteoblast specific markers are present in calcified atherosclerotic lesions, highlighting the relevance of these events in atherosclerosis (Dhore et al., 2001; Engelse et al., 2001). Finally, VSMC can differentiate into macrophage-like cells. These cells are enlarged and characterized by lipid inclusions in the cytoplasm with immunoreactivity to $\alpha$-smooth muscle actin and vimentin, specific markers of VSMC. These cells are present in human atherosclerotic lesions (Vukovic et al., 2006)

Some effort was made to study the effect of iron on the phenotype switching of VSMC. Iron chelation by desferoxamine (DFO) significantly inhibited VSMC proliferation, a hallmark of the synthetic phenotype in vitro (Porreca et al., 1994; Wong et al., 2012), although opposing results show that iron decrease VSMC growth (Mueller et al., 2006). Iron chelation inhibits the pathological vascular remodeling response induced by balloon injury and pulmonary hypertension (Porreca et al., 1994; Wong et al., 2012). Accumulating evidence indicates that heme, and in particular, products of heme catabolism by $\mathrm{HO}-1$ regulate VSMC growth (reviewed in Durante, 2003). Carbon monoxide directly inhibits VSMC proliferation by arresting cells in the $G_{0} / G_{1}$ phase of the cell cycle, whereas biliverdin and bilirubin induce VSMC apoptosis (Morita et al., 1997; Liu et al., 2002; Peyton et al., 2002).

Recently, by studying the effect of iron on osteochondrogenic differentiation of VSMC, iron was reported to inhibit inorganic phosphate $(\mathrm{Pi})$-mediated osteoblastic transition and subsequent mineralization of VSMCs in vitro (Zarjou et al., 2009). Importantly, iron inhibited the Pi-mediated increase in the expression of core binding factor-1 (Cbfa-1), the key osteoblastspecific transcription factor orchestrating the production of osteoblast-specific proteins, such as alkaline phosphatase and osteocalcin (Zarjou et al., 2009). Ferritin was identified as the major protective molecule behind iron-mediated inhibition of mineralization. The inhibitory effect of ferritin is strictly dependent on its ferroxidase activity but not on its iron-storage ability (Zarjou et al., 2009). Although a direct evidence of a role for iron in calcification in vivo is lacking, recently it has been described that iron and calcium show a highly significant spatial inverse correlation within the atherosclerotic lesions (Rajendran et al., 2012).

Although increasing evidence suggests the critical role of VSMC phenotype switch in atherogenesis, the role of iron in these mechanisms still remains to be elucidated. Further in vitro and in vivo studies are essential to clarify the particular role of iron in differentiation of VSMC into synthetic, inflammatory, osteochondrogenic, or macrophage-like phenotypes.

\section{CONCLUSIVE REMARKS}

Over the last 30 years, several studies in animals and humans assessed the effect of increased body iron levels on atherosclerosis, yielding conflicting results. In the last decade, our understanding of $\mathrm{Hb}$ and iron biology underwent a radical revision. This significantly helped in understanding the atherogenic effects of iron and iron-containing molecules. Numerous experiments support the idea that oxidized $\mathrm{Hb}$, Heme, and iron-by interacting with plaque lipids, promoting endothelial dysfunction, dictating macrophage polarization, modulating 
VSMC phenotype and proliferation-may affect the atherogenic process. Complex systems have evolved to control and dispose cell-free $\mathrm{Hb}$, heme, and iron but these systems may be eventually overwhelmed upon excessive hemorrhage or hemolysis and upon pathological iron overload. However, to date, the impact of iron on atherosclerosis is still debated. Future studies are required to clearly address whether iron overload is a risk factor for atherosclerosis and what iron source - systemic, tissue or macrophage iron-mainly affects the atherosclerotic process. Comprehensive understanding the role of iron on atherogenesis may lead to the development of improved diagnostics and therapeutics meant to interrupt the pathologic actions of excess iron.

\section{AUTHOR CONTRIBUTIONS}

All authors contributed to the conception and design of this review. Viktória Jeney, Francesca Vinchi, and Milene Costa Da Silva wrote the manuscript, designed and made the figures. The manuscript was critically revised by Martina U. Muckenthaler, József Balla, and György Balla.

\section{ACKNOWLEDGMENTS}

The research group is supported by the Hungarian Academy of Sciences (11003). This work was supported by Hungarian Government grants OTKA-K75883 (György Balla), OTKAK83478 (József Balla), OTKA- PD83435 (Viktória Jeney), European Reintegration Grant FP7-PEOPLE-2010-268332 (Viktória Jeney), and by the TÁMOP 4.2.2.A-11/1/KONV-20120045 projects. The project is co-financed by the European Union and the European Social Fund. This work was supported by a Postdoctoral-Fellowship granted to Francesca Vinchi from the Medical Faculty of the University of Heidelberg, Germany (http://www.medizinische-fakultaet-hd.uni-heidelberg.de).

\section{REFERENCES}

Aessopos, A., Farmakis, D., Tsironi, M., Diamanti-Kandarakis, E., Matzourani, M., Fragodimiri, C., et al. (2007). Endothelial function and arterial stiffness in sickle-thalassemia patients. Atherosclerosis 191, 427-432. doi: 10.1016/j.atherosclerosis.2006.04.015

Ahluwalia, N., Genoux, A., Ferrieres, J., Perret, B., Carayol, M., Drouet, L., et al. (2010). Iron status is associated with carotid atherosclerotic plaques in middleaged adults. J. Nutr. 140, 812-816. doi: 10.3945/jn.109.110353

Alayash, A. I. (2011). Haptoglobin: old protein with new functions. Clin. Chim. Acta 412, 493-498. doi: 10.1016/j.cca.2010.12.011

Araujo, J. A., Romano, E. L., Brito, B. E., Parthe, V., Romano, M., Bracho, M., et al. (1995). Iron overload augments the development of atherosclerotic lesions in rabbits. Arterioscler. Thromb. Vasc. Biol. 15, 1172-1180. doi: 10.1161/01.ATV.15.8.1172

Bach, F. H. (2005). Heme oxygenase-1: a therapeutic amplification funnel. FASEB J. 19, 1216-1219. doi: 10.1096/fj.04-3485cmt

Bagheri, B., Shokrzadeh, M., Mokhberi, V., Azizi, A., Khalilian, A., Akbari, N., et al. (2013). Association between serum iron and the severity of coronary artery disease. I. Cardiovasc. Res. J. 7, 95-98.

Balla, G., Jacob, H. S., Eaton, J. W., Belcher, J. D., and Vercellotti, G. M. (1991a). Hemin: a possible physiological mediator of low density lipoprotein oxidation and endothelial injury. Arterioscler. Thromb. 11, 1700-1711. doi: 10.1161/01.ATV.11.6.1700

Balla, G., Vercellotti, G. M., Muller-Eberhard, U., Eaton, J., and Jacob, H. S. (1991b). Exposure of endothelial cells to free heme potentiates damage mediated by granulocytes and toxic oxygen species. Lab. Invest. 64, 648-655.
Balla, J., Jacob, H. S., Balla, G., Nath, K., Eaton, J. W., and Vercellotti, G. M. (1993). Endothelial-cell heme uptake from heme proteins: induction of sensitization and desensitization to oxidant damage. Proc. Natl. Acad. Sci. U.S.A. 90, 9285-9289. doi: 10.1073/pnas.90.20.9285

Balla, J., Vercellotti, G. M., Jeney, V., Yachie, A., Varga, Z., Eaton, J. W., et al. (2005). Heme, heme oxygenase and ferritin in vascular endothelial cell injury. Mol. Nutr. Food Res. 49, 1030-1043. doi: 10.1002/mnfr.200500076

Belcher, J. D., Chen, C., Nguyen, J., Milbauer, L., Abdulla, F., Alayash, A. I., et al. (2014). Heme triggers TLR4 signaling leading to endothelial cell activation and vaso-occlusion in murine sickle cell disease. Blood 123, 377-390. doi: 10.1182/blood-2013-04-495887

Belcher, J. D., Marker, P. H., Geiger, P., Girotti, A. W., Steinberg, M. H., Hebbel, R. P., et al. (1999). Low-density lipoprotein susceptibility to oxidation and cytotoxicity to endothelium in sickle cell anemia. J. Lab. Clin. Med. 133, 605-612. doi: 10.1016/S0022-2143(99)90191-9

Borgna-Pignatti, C., Rugolotto, S., De Stefano, P., Zhao, H., Cappellini, M. D., Del Vecchio, G. C., et al. (2004). Survival and complications in patients with thalassemia major treated with transfusion and deferoxamine. Haematologica 89, 1187-1193.

Bouhlel, M. A., Derudas, B., Rigamonti, E., Dievart, R., Brozek, J., Haulon, S., et al. (2007). PPARgamma activation primes human monocytes into alternative M2 macrophages with anti-inflammatory properties. Cell Metab. 6, 137-143. doi: 10.1016/j.cmet.2007.06.010

Boyle, J. J., Harrington, H. A., Piper, E., Elderfield, K., Stark, J., Landis, R. C., et al. (2009). Coronary intraplaque hemorrhage evokes a novel atheroprotective macrophage phenotype. Am. J. Pathol. 174, 1097-1108. doi: 10.2353/ajpath.2009.080431

Boyle, J. J., Johns, M., Kampfer, T., Nguyen, A. T., Game, L., Schaer, D. J., et al. (2011a). Activating transcription factor 1 directs Mhem atheroprotective macrophages through coordinated iron handling and foam cell protection. Circ. Res. 110, 20-33. doi: 10.1161/CIRCRESAHA.111.247577

Boyle, J. J., Johns, M., Lo, J., Chiodini, A., Ambrose, N., Evans, P. C., et al. (2011b). Heme induces heme oxygenase 1 via Nrf2: role in the homeostatic macrophage response to intraplaque hemorrhage. Arterioscler. Thromb. Vasc. Biol. 31, 2685-2691. doi: 10.1161/ATVBAHA.111.225813

Brissot, P., Ropert, M., Le Lan, C., and Loreal, O. (2012). Non-transferrin bound iron: a key role in iron overload and iron toxicity. Biochim. Biophys. Acta 1820, 403-410. doi: 10.1016/j.bbagen.2011.07.014

Brizzi, P., Isaja, T., D’agata, A., Malaguarnera, L., Malaguarnera, M., and Musumeci, S. (2002). Oxidized LDL antibodies (OLAB) in patients with beta-thalassemia major. J. Atheroscler. Thromb. 9, 139-144. doi: 10.5551/jat.9.139

Brouwers, A., Langlois, M., Delanghe, J., Billiet, J., De Buyzere, M., Vercaemst, R., et al. (2004). Oxidized low-density lipoprotein, iron stores, and haptoglobin polymorphism. Atherosclerosis 176, 189-195. doi: 10.1016/j.atherosclerosis.2004.05.005

Brunet, S., Thibault, L., Delvin, E., Yotov, W., Bendayan, M., and Levy, E. (1999). Dietary iron overload and induced lipid peroxidation are associated with impaired plasma lipid transport and hepatic sterol metabolism in rats. Hepatology 29, 1809-1817. doi: 10.1002/hep.510290612

Butcher, M. J., and Galkina, E. V. (2012). Phenotypic and functional heterogeneity of macrophages and dendritic cell subsets in the healthy and atherosclerosisprone aorta. Front. Physiol. 3:44. doi: 10.3389/fphys.2012.00044

Cairo, G., Recalcati, S., Mantovani, A., and Locati, M. (2011). Iron trafficking and metabolism in macrophages: contribution to the polarized phenotype. Trends Immunol. 32, 241-247. doi: 10.1016/j.it.2011.03.007

Campbell, G. R., and Campbell, J. H. (1985). Smooth muscle phenotypic changes in arterial wall homeostasis: implications for the pathogenesis of atherosclerosis. Exp. Mol. Pathol. 42, 139-162. doi: 10.1016/0014-4800(85)90023-1

Carlier, S., Kakadiaris, I. A., Dib, N., Vavuranakis, M., O’malley, S. M., Gul, K., et al. (2005). Vasa vasorum imaging: a new window to the clinical detection of vulnerable atherosclerotic plaques. Curr. Atheroscler. Rep. 7, 164-169. doi: 10.1007/s11883-005-0040-2

Casanova-Esteban, P., Guiral, N., Andres, E., Gonzalvo, C., Mateo-Gallego, R., Giraldo, P., et al. (2011). Effect of phlebotomy on lipid metabolism in subjects with hereditary hemochromatosis. Metab. Clin. Exp. 60, 830-834. doi: 10.1016/j.metabol.2010.07.035

Chan, K. H., Ng, M. K., and Stocker, R. (2011). Haem oxygenase-1 and cardiovascular disease: mechanisms and therapeutic potential. Clin. Sci. 120, 493-504. doi: $10.1042 / C S 20100508$ 
Chapple, S. J., Cheng, X., and Mann, G. E. (2013). Effects of 4-hydroxynonenal on vascular endothelial and smooth muscle cell redox signaling and function in health and disease. Redox Biol. 1, 319-331. doi: 10.1016/j.redox.2013.04.001

Cheng, C., Noordeloos, A. M., Jeney, V., Soares, M. P., Moll, F., Pasterkamp, G., et al. (2009). Heme oxygenase 1 determines atherosclerotic lesion progression into a vulnerable plaque. Circulation 119, 3017-3027. doi: 10.1161/CIRCULATIONAHA.108.808618

Cheung, Y. F., Chan, G. C., and Ha, S. Y. (2002). Arterial stiffness and endothelial function in patients with beta-thalassemia major. Circulation 106, 2561-2566. doi: 10.1161/01.CIR.0000037225.92759.A7

Cheung, Y. F., Chan, G. C., and Ha, S. Y. (2008). Effect of deferasirox (ICL670) on arterial function in patients with beta-thalassaemia major. Br. J. Haematol. 141, 728-733. doi: 10.1111/j.1365-2141.2008.07092.x

Cheung, Y. F., Chow, P. C., Chan, G. C., and Ha, S. Y. (2006). Carotid intimamedia thickness is increased and related to arterial stiffening in patients with beta-thalassaemia major. Br. J. Haematol. 135, 732-734. doi: 10.1111/j.13652141.2006.06349.x

Chinetti-Gbaguidi, G., Baron, M., Bouhlel, M. A., Vanhoutte, J., Copin, C., Sebti, Y., et al. (2011). Human atherosclerotic plaque alternative macrophages display low cholesterol handling but high phagocytosis because of distinct activities of the PPARgamma and LXRalpha pathways. Circ. Res. 108, 985-995. doi: 10.1161/CIRCRESAHA.110.233775

Costacou, T., and Levy, A. P. (2012). Haptoglobin genotype and its role in diabetic cardiovascular disease. J. Cardiovasc. Transl. Res. 5, 423-435. doi: 10.1007/s12265-012-9361-z

Dabbagh, A. J., Shwaery, G. T., Keaney, J. F. Jr., and Frei, B. (1997). Effect of iron overload and iron deficiency on atherosclerosis in the hypercholesterolemic rabbit. Arterioscler. Thromb. Vasc. Biol. 17, 2638-2645. doi: 10.1161/01.ATV.17.11.2638

de Chadarevian, J. P., Balarezo, F. S., Heggere, M., and Dampier, C. (2001). Splenic arteries and veins in pediatric sickle cell disease. Pediatr. Dev. Pathol. 4, 538-544. doi: 10.1007/s10024001-0045-y

den Dekker, W. K., Cheng, C., Pasterkamp, G., and Duckers, H. J. (2010). Toll like receptor 4 in atherosclerosis and plaque destabilization. Atherosclerosis 209, 314-320. doi: 10.1016/j.atherosclerosis.2009.09.075

Depalma, R. G., Hayes, V. W., Chow, B. K., Shamayeva, G., May, P. E., and Zacharski, L. R. (2010). Ferritin levels, inflammatory biomarkers, and mortality in peripheral arterial disease: a substudy of the Iron $(\mathrm{Fe})$ and Atherosclerosis Study (FeAST) Trial. J. Vasc. Surg. 51, 1498-1503. doi: 10.1016/j.jvs. 2009.12.068

Dhore, C. R., Cleutjens, J. P., Lutgens, E., Cleutjens, K. B., Geusens, P. P., Kitslaar, P. J., et al. (2001). Differential expression of bone matrix regulatory proteins in human atherosclerotic plaques. Arterioscler. Thromb. Vasc. Biol. 21, 1998-2003. doi: $10.1161 /$ hq1201.100229

Duffy, S. J., Biegelsen, E. S., Holbrook, M., Russell, J. D., Gokce, N., Keaney, J. F., et al. (2001). Iron chelation improves endothelial function in patients with coronary artery disease. Circulation 103, 2799-2804. doi: 10.1161/01.CIR.103.23.2799

Durante, W. (2003). Heme oxygenase-1 in growth control and its clinical application to vascular disease. J. Cell. Physiol. 195, 373-382. doi: 10.1002/jcp.10274

Durante, W. (2011). Protective role of heme oxygenase-1 against inflammation in atherosclerosis. Front. Biosci. 16, 2372-2388. doi: 10.2741/3860

Eisenstein, R. S., Garcia-Mayol, D., Pettingell, W., and Munro, H. N. (1991). Regulation of ferritin and heme oxygenase synthesis in rat fibroblasts by different forms of iron. Proc. Natl. Acad. Sci. U.S.A. 88, 688-692. doi: 10.1073/pnas.88.3.688

Elsharawy, M. A., Moghazy, K. M., and Shawarby, M. A. (2009). Atherosclerosis in sickle cell disease-a review. Int. J. Angiol. 18, 62-66. doi: 10.1055/s-00311278326

Engelse, M. A., Neele, J. A., Bronckers, A. L. J. J., Pannekoek, H., and De Vries, C. J. M. (2001). Vascular calcification: expression patterns of the osteoblast-specific gene core binding factor alpha-1 and the protective factor matrix gla protein in human atherogenesis. Cardiovasc. Res. 52, 281-289. doi: 10.1016/S00086363(01)00375-3

Erdogan, D., Gullu, H., Yildirim, E., Tok, D., Kirbas, I., Ciftci, O., et al. (2006). Low serum bilirubin levels are independently and inversely related to impaired flow-mediated vasodilation and increased carotid intima-media thickness in both men and women. Atherosclerosis 184, 431-437. doi: 10.1016/j.atherosclerosis.2005.05.011
Erkan, A., Ekici, B., Ugurlu, M., Is, G., Seker, R., Demirtas, S., et al. (2013). The role of bilirubin and its protective function against coronary heart disease. Herz. doi: 10.1007/s00059-013-3872-5. [Epub ahead of print].

Failla, M., Giannattasio, C., Piperno, A., Vergani, A., Grappiolo, A., Gentile, G., et al. (2000). Radial artery wall alterations in genetic hemochromatosis before and after iron depletion therapy. Hepatology 32, 569-573. doi: 10.1053/jhep.2000.16265

Feldman, H. I., Joffe, M., Robinson, B., Knauss, J., Cizman, B., Guo, W., et al. (2004). Administration of parenteral iron and mortality among hemodialysis patients. J. Am. Soc. Nephrol. 15, 1623-1632. doi: 10.1097/01.ASN.0000128009.69594.BE

Ferrara, D. E., and Taylor, W. R. (2005). Iron chelation and vascular function: in search of the mechanisms. Arterioscler. Thromb. Vasc. Biol. 25, 2235-2237. doi: 10.1161/01.ATV.0000189303.45609.1f

Ferris, C. D., Jaffrey, S. R., Sawa, A., Takahashi, M., Brady, S. D., Barrow, R. K., et al. (1999). Haem oxygenase-1 prevents cell death by regulating cellular iron. Nat. Cell Biol. 1, 152-157. doi: 10.1038/11072

Figueiredo, R. T., Fernandez, P. L., Mourao-Sa, D. S., Porto, B. N., Dutra, F. F., Alves, L. S., et al. (2007). Characterization of heme as activator of Toll-like receptor 4. J. Biol. Chem. 282, 20221-20229. doi: 10.1074/jbc.M610737200

Finn, A.V., Nakano, M., Polavarapu, R., Karmali, V., Saeed, O., Zhao, X., et al. (2012). Hemoglobin directs macrophage differentiation and prevents foam cell formation in human atherosclerotic plaques. J. Am. Coll. Cardiol. 59, 166-177. doi: 10.1016/j.jacc.2011.10.852

Fleming, R. E., Feng, Q., and Britton, R. S. (2011). Knockout mouse models of iron homeostasis. Annu. Rev. Nutr. 31, 117-137. doi: 10.1146/annurev-nutr-072610145117

Francis, R. B. Jr., and Johnson, C. S. (1991). Vascular occlusion in sickle cell disease: current concepts and unanswered questions. Blood 77, 1405-1414.

Gaenzer, H., Marschang, P., Sturm, W., Neumayr, G., Vogel, W., Patsch, J., et al. (2002). Association between increased iron stores and impaired endothelial function in patients with hereditary hemochromatosis. J. Am. Coll. Cardiol. 40, 2189-2194. doi: 10.1016/S0735-1097(02)02611-6

Ganz, T., and Nemeth, E. (2011). Hepcidin and disorders of iron metabolism. Annu. Rev. Med. 62, 347-360. doi: 10.1146/annurev-med-050109-142444

Ghosh, S., Adisa, O. A., Chappa, P., Tan, F., Jackson, K. A., Archer, D. R., et al. (2013). Extracellular hemin crisis triggers acute chest syndrome in sickle mice. J. Clin. Invest. 123, 4809-4820. doi: 10.1172/JCI64578

Giachelli, C. M. (2003). Vascular calcification: in vitro evidence for the role of inorganic phosphate. J. Am. Soc. Nephrol. 14, S300-S304. doi: 10.1097/01.ASN.0000081663.52165.66

Giachelli, C. M., Jono, S., Shioi, A., Nishizawa, Y., Mori, K., and Morii, H. (2001). Vascular calcification and inorganic phosphate. Am. J. Kidney Dis. 38, S34-S37. doi: 10.1053/ajkd.2001.27394

Gillum, R. F., Mussolino, M. E., and Madans, J. H. (1997). Coronary heart disease incidence and survival in African-American women and men. The NHANES I epidemiologic follow-up study. Ann. Intern. Med. 127, 111-118. doi: 10.7326/0003-4819-127-2-199707150-00003

Gleissner, C. A. (2012). Macrophage phenotype modulation by CXCL4 in Atherosclerosis. Front. Physiol. 3:1. doi: 10.3389/fphys.2012.00001

Gleissner, C. A., Shaked, I., Erbel, C., Bockler, D., Katus, H. A., and Ley, K. (2010a). CXCL4 downregulates the atheroprotective hemoglobin receptor CD163 in human macrophages. Circ. Res. 106, 203-211. doi: 10.1161/CIRCRESAHA.109.199505

Gleissner, C. A., Shaked, I., Little, K. M., and Ley, K. (2010b). CXC chemokine ligand 4 induces a unique transcriptome in monocyte-derived macrophages. J. Immunol. 184, 4810-4818. doi: 10.4049/jimmunol.0901368

Goldenstein, H., Levy, N. S., and Levy, A. P. (2012). Haptoglobin genotype and its role in determining heme-iron mediated vascular disease. Pharmacol. Res. 66, 1-6. doi: 10.1016/j.phrs.2012.02.011

Gozzelino, R., Jeney, V., and Soares, M. P. (2010). Mechanisms of cell protection by heme oxygenase-1. Annu. Rev. Pharmacol. Toxicol. 50, 323-354. doi: 10.1146/annurev.pharmtox.010909.105600

Graham, J. K., Mosunjac, M., and Hanzlick, R. L. (2007). Sickle cell lung disease and sudden death: a retrospective/prospective study of 21 autopsy cases and literature review. Am. J. Forensic Med. Pathol. 28, 168-172. doi: 10.1097/01.paf.0000257397.92466.50

Gustafsson, H., Hallbeck, M., Norell, M., Lindgren, M., Engstrom, M., Rosen, A., et al. (2013). Fe(III) distribution varies substantially within 
and between atherosclerotic plaques. Magn. Reson. Med. 71, 885-892. doi: $10.1002 / \mathrm{mrm} .24687$

Hahalis, G., Kremastinos, D. T., Terzis, G., Kalogeropoulos, A. P., Chrysanthopoulou, A., Karakantza, M., et al. (2008). Global vasomotor dysfunction and accelerated vascular aging in beta-thalassemia major. Atherosclerosis 198, 448-457. doi: 10.1016/j.atherosclerosis.2007. 09.030

Haidari, M., Javadi, E., Sanati, A., Hajilooi, M., and Ghanbili, J. (2001). Association of increased ferritin with premature coronary stenosis in men. Clin. Chem. 47, 1666-1672.

Harrison, P. M., and Arosio, P. (1996). The ferritins: molecular properties, iron storage function and cellular regulation. Biochim. Biophys. Acta 1275, 161-203. doi: 10.1016/0005-2728(96)00022-9

Heinecke, J. W., Rosen, H., and Chait, A. (1984). Iron and copper promote modification of low density lipoprotein by human arterial smooth muscle cells in culture. J. Clin. Invest. 74, 1890-1894. doi: 10.1172/JCI111609

Hentze, M. W., Muckenthaler, M. U., Galy, B., and Camaschella, C. (2010). Two to tango: regulation of Mammalian iron metabolism. Cell 142, 24-38. doi: 10.1016/j.cell.2010.06.028

Holay, M. P., Choudhary, A. A., and Suryawanshi, S. D. (2012). Serum ferritin-a novel risk factor in acute myocardial infarction. Indian Heart J. 64, 173-177. doi: 10.1016/S0019-4832(12)60056-X

Houschyar, K. S., Ludtke, R., Dobos, G. J., Kalus, U., Broecker-Preuss, M., Rampp, T., et al. (2012). Effects of phlebotomy-induced reduction of body iron stores on metabolic syndrome: results from a randomized clinical trial. BMC Med. 10:54. doi: 10.1186/1741-7015-10-54

Hulley, S., Grady, D., Bush, T., Furberg, C., Herrington, D., Riggs, B., et al. (1998). Randomized trial of estrogen plus progestin for secondary prevention of coronary heart disease in postmenopausal women. JAMA 280, 605-613. doi: 10.1001/jama.280.7.605

Ijas, P., Saksi, J., Soinne, L., Tuimala, J., Jauhiainen, M., Jula, A., et al. (2013). Haptoglobin 2 allele associates with unstable carotid plaque and major cardiovascular events. Atherosclerosis 230, 228-234. doi: 10.1016/j.atherosclerosis.2013.07.008

Ishikawa, K., Navab, M., and Lusis, A. J. (2012). Vasculitis, Atherosclerosis, and altered HDL composition in heme-oxygenase-1-knockout mice. Int. J. Hypertens. 2012:948203. doi: 10.1155/2012/948203

Ishizaka, N., Saito, K., Mori, I., Matsuzaki, G., Ohno, M., and Nagai, R. (2005). Iron chelation suppresses ferritin upregulation and attenuates vascular dysfunction in the aorta of angiotensin II-infused rats. Arterioscler. Thromb. Vasc. Biol. 25, 2282-2288. doi: 10.1161/01.ATV.0000181763.57495.2b

Jayachandran, M., Miller, V. M., Brunn, G. J., and Owen, W. G. (2010). Platelet response as a sentinel marker of toll-like receptor 4 activation in mice. Thromb. Res. 126, 414-417. doi: 10.1016/j.thromres.2009.05.005

Jehn, M., Clark, J. M., and Guallar, E. (2004). Serum ferritin and risk of the metabolic syndrome in U.S. adults. Diabetes Care 27, 2422-2428. doi: 10.2337/diacare.27.10.2422

Jehn, M. L., Guallar, E., Clark, J. M., Couper, D., Duncan, B. B., Ballantyne, C. M., et al. (2007). A prospective study of plasma ferritin level and incident diabetes: the Atherosclerosis Risk in Communities (ARIC) Study. Am. J. Epidemiol. 165, 1047-1054. doi: 10.1093/aje/kwk093

Jeney, V., Balla, J., Yachie, A., Varga, Z., Vercellotti, G. M., Eaton, J. W., et al. (2002). Pro-oxidant and cytotoxic effects of circulating heme. Blood 100, 879-887. doi: 10.1182/blood.V100.3.879

Jeney, V., Eaton, J. W., Balla, G., and Balla, J. (2013). Natural history of the bruise: formation, elimination, and biological effects of oxidized hemoglobin. Oxid. Med. Cell. Longev. 2013:703571. doi: 10.1155/2013/703571

Jono, S., Mckee, M. D., Murry, C. E., Shioi, A., Nishizawa, Y., Mori, K., et al. (2000). Phosphate regulation of vascular smooth muscle cell calcification. Circ. Res. 87, E10-E17. doi: 10.1161/01.RES.87.7.e10

Juan, S. H., Lee, T. S., Tseng, K. W., Liou, J. Y., Shyue, S. K., Wu, K. K., et al. (2001). Adenovirus-mediated heme oxygenase- 1 gene transfer inhibits the development of atherosclerosis in apolipoprotein E-deficient mice. Circulation 104, 1519-1525. doi: 10.1161/hc3801.095663

Julius, U., and Pietzsch, J. (2005). Glucose-induced enhancement of hemincatalyzed LDL oxidation in vitro and in vivo. Antioxid. Redox Signal. 7, 1507-1512. doi: 10.1089/ars.2005.7.1507

Kadl, A., Meher, A. K., Sharma, P. R., Lee, M. Y., Doran, A. C., Johnstone, S. R., et al. (2010). Identification of a novel macrophage phenotype that develops in response to atherogenic phospholipids via Nrf2. Circ. Res. 107, 737-746. doi: 10.1161/CIRCRESAHA.109.215715

Kalantar-Zadeh, K., Don, B. R., Rodriguez, R. A., and Humphreys, M. H. (2001). Serum ferritin is a marker of morbidity and mortality in hemodialysis patients. Am. J. Kidney Dis. 37, 564-572. doi: 10.1053/ajkd.2001.22433

Kalantar-Zadeh, K., Rodriguez, R. A., and Humphreys, M. H. (2004). Association between serum ferritin and measures of inflammation, nutrition and iron in haemodialysis patients. Nephrol. Dial. Transplant. 19, 141-149. doi: 10.1093/ndt/gfg493

Kamanna, V. S., Ganji, S. H., Shelkovnikov, S., Norris, K., and Vaziri, N. D. (2012). Iron sucrose promotes endothelial injury and dysfunction and monocyte adhesion/infiltration. Am. J. Nephrol. 35, 114-119. doi: 10.1159/000334939

Kaneda, H., Ohno, M., Taguchi, J., Togo, M., Hashimoto, H., Ogasawara, K., et al. (2002). Heme oxygenase-1 gene promoter polymorphism is associated with coronary artery disease in Japanese patients with coronary risk factors. Arterioscler. Thromb. Vasc. Biol. 22, 1680-1685. doi: 10.1161/01.ATV.0000033515.96747.6F

Kannel, W. B., Hjortland, M. C., Mcnamara, P. M., and Gordon, T. (1976) Menopause and risk of cardiovascular disease: the Framingham study. Ann. Intern. Med. 85, 447-452. doi: 10.7326/0003-4819-85-4-447

Kartikasari, A. E., Georgiou, N. A., Visseren, F. L., Van Kats-Renaud, H., Van Asbeck, B. S., and Marx, J. J. (2006). Endothelial activation and induction of monocyte adhesion by nontransferrin-bound iron present in human sera. FASEB J. 20, 353-355. doi: 10.1096/fj.05-4700fje

Kautz, L., Gabayan, V., Wang, X., Wu, J., Onwuzurike, J., Jung, G., et al. (2013). Testing the iron hypothesis in a mouse model of atherosclerosis. Cell Rep. 5, 1436-1442. doi: 10.1016/j.celrep.2013.11.009

Khallou-Laschet, J., Varthaman, A., Fornasa, G., Compain, C., Gaston, A. T., Clement, M., et al. (2010). Macrophage plasticity in experimental atherosclerosis. PLoS ONE 5:e8852. doi: 10.1371/journal.pone.0008852

Kiechl, S., and Willeit, J. (1999). The natural course of atherosclerosis. Part II: vascular remodeling. Bruneck Study Group. Arterioscler. Thromb. Vasc. Biol. 19, 1491-1498. doi: 10.1161/01.ATV.19.6.1491

Kiechl, S., Willeit, J., Egger, G., Poewe, W., and Oberhollenzer, F. (1997). Body iron stores and the risk of carotid atherosclerosis: prospective results from the Bruneck study. Circulation 96, 3300-3307. doi: 10.1161/01.CIR.96.10.3300

Kimm, H., Yun, J. E., Jo, J., and Jee, S. H. (2009). Low serum bilirubin level as an independent predictor of stroke incidence: a prospective study in Korean men and women. Stroke 40, 3422-3427. doi: 10.1161/STROKEAHA.109.560649

Kirk, E. A., Heinecke, J. W., and Leboeuf, R. C. (2001). Iron overload diminishes atherosclerosis in apoE-deficient mice. J. Clin. Invest. 107, 1545-1553. doi: 10.1172/JCI7664

Kleemann, R., Zadelaar, S., and Kooistra, T. (2008). Cytokines and atherosclerosis: a comprehensive review of studies in mice. Cardiovasc. Res. 79, 360-376. doi: $10.1093 / \mathrm{cvr} / \mathrm{cvn} 120$

Kletzmayr, J., and Horl, W. H. (2002). Iron overload and cardiovascular complications in dialysis patients. Nephrol. Dial. Transplant. 17(Suppl. 2), 25-29. doi: 10.1093/ndt/17.suppl_2.25

Klouche, K., Morena, M., Canaud, B., Descomps, B., Beraud, J. J., and Cristol, J. P. (2004). Mechanism of in vitro heme-induced LDL oxidation: effects of antioxidants. Eur. J. Clin. Invest. 34, 619-625. doi: 10.1111/j.1365-2362.2004.01395.x

Kolodgie, F. D., Gold, H. K., Burke, A. P., Fowler, D. R., Kruth, H. S., Weber, D. K., et al. (2003). Intraplaque hemorrhage and progression of coronary atheroma. N. Engl. J. Med. 349, 2316-2325. doi: 10.1056/NEJMoa035655

Kolodgie, F. D., Virmani, R., Burke, A. P., Farb, A., Weber, D. K., Kutys, R., et al. (2004). Pathologic assessment of the vulnerable human coronary plaque. Heart 90, 1385-1391. doi: 10.1136/hrt.2004.041798

Kremastinos, D. T., Flevari, P., Spyropoulou, M., Vrettou, H., Tsiapras, D., and Stavropoulos-Giokas, C. G. (1999). Association of heart failure in homozygous beta-thalassemia with the major histocompatibility complex. Circulation 100, 2074-2078. doi: 10.1161/01.CIR.100.20.2074

Kristiansen, M., Graversen, J. H., Jacobsen, C., Sonne, O., Hoffman, H. J., Law, S. K., et al. (2001). Identification of the haemoglobin scavenger receptor. Nature 409, 198-201. doi: 10.1038/35051594

Kunsch, C., and Medford, R. M. (1999). Oxidative stress as a regulator of gene expression in the vasculature. Circ. Res. 85, 753-766. doi: 10.1161/01.RES.85.8.753

Kuo, K. L., Hung, S. C., Lin, Y. P., Tang, C. F., Lee, T. S., Lin, C. P., et al. (2012). Intravenous ferric chloride hexahydrate supplementation induced endothelial 
dysfunction and increased cardiovascular risk among hemodialysis patients. PLoS ONE 7:e50295. doi: 10.1371/journal.pone.0050295

Landis, R. C., Philippidis, P., Domin, J., Boyle, J. J., and Haskard, D. O. (2013). Haptoglobin Genotype-Dependent Anti-Inflammatory Signaling in CD163(+) Macrophages. Int. J. Inflam. 2013:980327. doi: 10.1155/2013/980327

Lauffer, R. B. (1990). Iron depletion and coronary disease. Am. Heart J. 119, 1448-1449. doi: 10.1016/S0002-8703(05)80216-9

Lecube, A., Hernandez, C., Pelegri, D., and Simo, R. (2008). Factors accounting for high ferritin levels in obesity. Int. J. Obes. 32, 1665-1669. doi: 10.1038/ijo.2008.154

Lee, H. T., Chiu, L. L., Lee, T. S., Tsai, H. L., and Chau, L. Y. (2003). Dietary iron restriction increases plaque stability in apolipoprotein-e-deficient mice. J. Biomed. Sci. 10, 510-517. doi: 10.1007/BF02256112

Lee, T. S., Shiao, M. S., Pan, C. C., and Chau, L. Y. (1999). Iron-deficient diet reduces atherosclerotic lesions in apoE-deficient mice. Circulation 99, 1222-1229. doi: 10.1161/01.CIR.99.9.1222

Leitinger, N., and Schulman, I. G. (2013). Phenotypic polarization of macrophages in atherosclerosis. Arterioscler. Thromb. Vasc. Biol. 33, 1120-1126. doi: 10.1161/ATVBAHA.112.300173

Li, J. J., Meng, X., Si, H. P., Zhang, C., Lv, H. X., Zhao, Y. X., et al. (2012). Hepcidin destabilizes atherosclerotic plaque via overactivating macrophages after erythrophagocytosis. Arterioscler. Thromb. Vasc. Biol. 32, 1158-1166. doi: 10.1161/ATVBAHA.112.246108

Liang, K. W., Sheu, W. H., Lee, W. L., Lee, I. T., Lin, S. Y., Ting, C. T., et al. (2013). Shorter GT repeats in the heme oxygenase-1 gene promoter are associated with a lower severity score in coronary artery disease. J. Chin. Med. Assoc. 76, 312-318. doi: 10.1016/j.jcma.2013.03.005

Libby, P. (2002). Inflammation in atherosclerosis. Nature 420, 868-874. doi: 10.1038 /nature 01323

Lioupis, C., Barbatis, C., Drougou, A., Koliaraki, V., Mamalaki, A., Klonaris, C., et al. (2011). Association of haptoglobin genotype and common cardiovascular risk factors with the amount of iron in atherosclerotic carotid plaques. Atherosclerosis 216, 131-138. doi: 10.1016/j.atherosclerosis.2011.01.028

Lioupis, C., Barbatis, C., Lazari, P., Liasis, N., Klonaris, C., Georgopoulos, S., et al. (2012). Macrophage infiltration and smooth muscle cells content associated with haptoglobin genotype in human atherosclerotic carotid plaques. Angiology 63, 178-183. doi: 10.1177/0003319711410051

Lipiski, M., Deuel, J. W., Baek, J. H., Engelsberger, W. R., Buehler, P. W., and Schaer, D. J. (2013). Human Hp1-1 and Hp2-2 phenotype-specific haptoglobin therapeutics are both effective in vitro and in guinea pigs to attenuate hemoglobin toxicity. Antioxid. Redox Signal. 19, 1619-1633. doi: 10.1089/ars.2012.5089

Liu, X. M., Chapman, G. B., Wang, H., and Durante, W. (2002). Adenovirusmediated heme oxygenase-1 gene expression stimulates apoptosis in vascular smooth muscle cells. Circulation 105, 79-84. doi: 10.1161/hc0102.101369

Liu, Z., Wang, J., Huang, E., Gao, S., Li, H., Lu, J., et al. (2014). Tanshinone IIA suppresses cholesterol accumulation in human macrophages: role of haem oxygenase-1. J. Lipid Res. 55, 201-213. doi: 10.1194/jlr.M040394

Livrea, M. A., Tesoriere, L., Maggio, A., D’arpa, D., Pintaudi, A. M., and Pedone, E. (1998). Oxidative modification of low-density lipoprotein and atherogenetic risk in beta-thalassemia. Blood 92, 3936-3942.

Lublinghoff, N., Winkler, K., Winkelmann, B. R., Seelhorst, U., Wellnitz, B., Boehm, B. O., et al. (2009). Genetic variants of the promoter of the heme oxygenase1 gene and their influence on cardiovascular disease (the Ludwigshafen Risk and Cardiovascular Health study). BMC Med. Genet. 10:36. doi: 10.1186/14712350-10-36

Lynch, S. M., and Frei, B. (1993). Mechanisms of copper- and iron-dependent oxidative modification of human low density lipoprotein. J. Lipid Res. 34, 1745-1753.

Manousou, P., Kalambokis, G., Grillo, F., Watkins, J., Xirouchakis, E., Pleguezuelo, M., et al. (2011). Serum ferritin is a discriminant marker for both fibrosis and inflammation in histologically proven non-alcoholic fatty liver disease patients. Liver Int. 31, 730-739. doi: 10.1111/j.1478-3231.2011.02488.x

Martinet, W., and De Meyer, G. R. (2007). Selective depletion of macrophages in atherosclerotic plaques: myth, hype, or reality? Circ. Res. 100, 751-753. doi: 10.1161/01.RES.0000263397.14481.96

Martinez, F. O., Gordon, S., Locati, M., and Mantovani, A. (2006). Transcriptional profiling of the human monocyte-to-macrophage differentiation and polarization: new molecules and patterns of gene expression. J. Immunol. 177, 7303-7311.
Marui, N., Offermann, M. K., Swerlick, R., Kunsch, C., Rosen, C. A., Ahmad, M., et al. (1993). Vascular cell adhesion molecule-1 (VCAM-1) gene transcription and expression are regulated through an antioxidant-sensitive mechanism in human vascular endothelial cells. J. Clin. Invest. 92, 1866-1874. doi: 10.1172/JCI116778

Mayer, M. (2000). Association of serum bilirubin concentration with risk of coronary artery disease. Clin. Chem. 46, 1723-1727.

McLeod, C., Fleeman, N., Kirkham, J., Bagust, A., Boland, A., Chu, P., et al. (2009). Deferasirox for the treatment of iron overload associated with regular blood transfusions (transfusional haemosiderosis) in patients suffering with chronic anaemia: a systematic review and economic evaluation. Health Technol. Assess. 13, iii-iv, ix-xi, 1-121. doi: 10.3310/hta13010

Melamed-Frank, M., Lache, O., Enav, B. I., Szafranek, T., Levy, N. S., Ricklis, R. M., et al. (2001). Structure-function analysis of the antioxidant properties of haptoglobin. Blood 98, 3693-3698. doi: 10.1182/blood.V98. 13.3693

Menke, A., Fernandez-Real, J. M., Muntner, P., and Guallar, E. (2009). The association of biomarkers of iron status with peripheral arterial disease in US adults. BMC Cardiovasc. Disord. 9:34. doi: 10.1186/1471-2261-9-34

Meyers, D. G., Jensen, K. C., and Menitove, J. E. (2002). A historical cohort study of the effect of lowering body iron through blood donation on incident cardiac events. Transfusion 42, 1135-1139. doi: 10.1046/j.1537-2995.2002. 00186.x

Meyers, D. G., Strickland, D., Maloley, P. A., Seburg, J. K., Wilson, J. E., and Mcmanus, B. F. (1997). Possible association of a reduction in cardiovascular events with blood donation. Heart 78, 188-193.

Michel, J. B., Virmani, R., Arbustini, E., and Pasterkamp, G. (2011). Intraplaque haemorrhages as the trigger of plaque vulnerability. Eur. Heart J. 32, 1977-1985, 1985a, 1985b, 1985c. doi: 10.1093/eurheartj/ehr054

Miller, D. M., Grover, T. A., Nayini, N., and Aust, S. D. (1993). Xanthine oxidaseand iron-dependent lipid peroxidation. Arch. Biochem. Biophys. 301, 1-7. doi: 10.1006/abbi.1993.1107

Miller, M., and Hutchins, G. M. (1994). Hemochromatosis, multiorgan hemosiderosis, and coronary artery disease. JAMA 272, 231-233. doi: 10.1001/jama.1994.03520030073031

Miller, Y. I., Smith, A., Morgan, W. T., and Shaklai, N. (1996). Role of hemopexin in protection of low-density lipoprotein against hemoglobin-induced oxidation. Biochemistry 35, 13112-13117. doi: 10.1021/bi960737u

Minqin, R., Rajendran, R., Pan, N., Tan, B. K., Ong, W. Y., Watt, F., et al. (2005). The iron chelator desferrioxamine inhibits atherosclerotic lesion development and decreases lesion iron concentrations in the cholesterol-fed rabbit. Free Radic. Biol. Med. 38, 1206-1211. doi: 10.1016/j.freeradbiomed.2005. 01.008

Moran, C. J., Siegel, M. J., and Debaun, M. R. (1998). Sickle cell disease: imaging of cerebrovascular complications. Radiology 206, 311-321.

Moreno, P. R., Purushothaman, K. R., Fuster, V., Echeverri, D., Truszczynska, H., Sharma, S. K., et al. (2004). Plaque neovascularization is increased in ruptured atherosclerotic lesions of human aorta: implications for plaque vulnerability. Circulation 110, 2032-2038. doi: 10.1161/01.CIR.0000143233. 87854.23

Morita, T., Mitsialis, S. A., Koike, H., Liu, Y., and Kourembanas, S. (1997). Carbon monoxide controls the proliferation of hypoxic vascular smooth muscle cells. J. Biol. Chem. 272, 32804-32809. doi: 10.1074/jbc.272.52.32804

Morrison, H. I., Semenciw, R. M., Mao, Y., and Wigle, D. T. (1994). Serum iron and risk of fatal acute myocardial infarction. Epidemiology 5, 243-246. doi: 10.1097/00001648-199403000-00015

Mosser, D. M., and Edwards, J. P. (2008). Exploring the full spectrum of macrophage activation. Nat. Rev. Immunol. 8, 958-969. doi: 10.1038/nri2448

Mueller, P. P., May, T., Perz, A., Hauser, H., and Peuster, M. (2006). Control of smooth muscle cell proliferation by ferrous iron. Biomaterials 27, 2193-2200. doi: 10.1016/j.biomaterials.2005.10.042

Munoz-Bravo, C., Gutierrez-Bedmar, M., Gomez-Aracena, J., Garcia-Rodriguez, A., and Navajas, J. F. (2013). Iron: protector or risk factor for cardiovascular disease? Still controversial. Nutrients 5, 2384-2404. doi: 10.3390/nu5072384

Nagy, E., Eaton, J. W., Jeney, V., Soares, M. P., Varga, Z., Galajda, Z., et al. (2010). Red cells, hemoglobin, heme, iron, and atherogenesis. Arterioscler. Thromb. Vasc. Biol. 30, 1347-1353. doi: 10.1161/ATVBAHA.110.206433

Nagy, E., Jeney, V., Yachie, A., Szabo, R. P., Wagner, O., Vercellotti, G. M., et al. (2005). Oxidation of hemoglobin by lipid hydroperoxide associated with 
low-density lipoprotein (LDL) and increased cytotoxic effect by LDL oxidation in heme oxygenase-1 (HO-1) deficiency. Cell. Mol. Biol. 51, 377-385.

Orr, A. W., Hastings, N. E., Blackman, B. R., and Wamhoff, B. R. (2010). Complex regulation and function of the inflammatory smooth muscle cell phenotype in atherosclerosis. J. Vasc. Res. 47, 168-180. doi: 10.1159/000250095

Pang, J. H., Jiang, M. J., Chen, Y. L., Wang, F. W., Wang, D. L., Chu, S. H., et al. (1996). Increased ferritin gene expression in atherosclerotic lesions. J. Clin. Invest. 97, 2204-2212. doi: 10.1172/JCI118661

Parfenova, H., Leffler, C. W., Basuroy, S., Liu, J., and Fedinec, A. L. (2012). Antioxidant roles of heme oxygenase, carbon monoxide, and bilirubin in cerebral circulation during seizures. J. Cereb. Blood Flow Metab. 32, 1024-1034. doi: $10.1038 / j \mathrm{jbfm} .2012 .13$

Pasterkamp, G., Van Keulen, J. K., and De Kleijn, D. P. (2004). Role of Toll-like receptor 4 in the initiation and progression of atherosclerotic disease. Eur. J. Clin. Invest. 34, 328-334. doi: 10.1111/j.1365-2362.2004.01338.x

Peyton, K. J., Reyna, S. V., Chapman, G. B., Ensenat, D., Liu, X. M., Wang, H., et al. (2002). Heme oxygenase-1-derived carbon monoxide is an autocrine inhibitor of vascular smooth muscle cell growth. Blood 99, 4443-4448. doi: 10.1182/blood.V99.12.4443

Philippidis, P., Mason, J. C., Evans, B. J., Nadra, I., Taylor, K. M., Haskard, D. O., et al. (2004). Hemoglobin scavenger receptor CD163 mediates interleukin-10 release and heme oxygenase-1 synthesis: antiinflammatory monocyte-macrophage responses in vitro, in resolving skin blisters in vivo, and after cardiopulmonary bypass surgery. Circ. Res. 94, 119-126. doi: 10.1161/01.RES.0000109414.78907.F9

Platt, O. S., Brambilla, D. J., Rosse, W. F., Milner, P. F., Castro, O., Steinberg, M. H., et al. (1994). Mortality in sickle cell disease. Life expectancy and risk factors for early death. N. Engl. J. Med. 330, 1639-1644. doi: 10.1056/NEJM199406093302303

Pober, J. S., and Sessa, W. C. (2007). Evolving functions of endothelial cells in inflammation. Nat. Rev. Immunol. 7, 803-815. doi: 10.1038/nri2171

Pocsi, I., Jeney, V., Kertai, P., Emri, T., Gyemant, G., Fesus, L., et al. (2008). Fungal siderophores function as protective agents of LDL oxidation and are promising anti-atherosclerotic metabolites in functional food. Mol. Nutr. Food Res. 52, 1434-1447. doi: 10.1002/mnfr.200700467

Porreca, E., Ucchino, S., Di Febbo, C., Di Bartolomeo, N., Angelucci, D., Napolitano, A. M., et al. (1994). Antiproliferative effect of desferrioxamine on vascular smooth muscle cells in vitro and in vivo. Arterioscler Thromb. 14, 299-304. doi: 10.1161/01.ATV.14.2.299

Poss, K. D., and Tonegawa, S. (1997). Heme oxygenase 1 is required for mammalian iron reutilization. Proc. Natl. Acad. Sci. U.S.A. 94, 10919-10924. doi: 10.1073/pnas.94.20.10919

Potor, L., Banyai, E., Becs, G., Soares, M. P., Balla, G., Balla, J., et al. (2013). Atherogenesis may involve the prooxidant and proinflammatory effects of ferryl hemoglobin. Oxid. Med. Cell. Longev. 2013:676425. doi: 10.1155/2013/ 676425

Purushothaman, K. R., Purushothaman, M., Levy, A. P., Lento, P. A., Evrard, S., Kovacic, J. C., et al. (2012). Increased expression of oxidation-specific epitopes and apoptosis are associated with haptoglobin genotype: possible implications for plaque progression in human atherosclerosis. J. Am. Coll. Cardiol. 60, 112-119. doi: 10.1016/j.jacc.2012.04.011

Radhakrishnan, N., Yadav, S. P., Sachdeva, A., Pruthi, P. K., Sawhney, S., Piplani, T., et al. (2011). Human heme oxygenase-1 deficiency presenting with hemolysis, nephritis, and asplenia. J. Pediatr. Hematol. Oncol. 33, 74-78. doi: 10.1097/MPH.0b013e3181fd2aae

Rajapurkar, M. M., Shah, S. V., Lele, S. S., Hegde, U. N., Lensing, S. Y., Gohel, K., et al. (2011). Association of catalytic iron with cardiovascular disease. Am. J. Cardiol. 109, 438-442. doi: 10.1016/j.amjcard.2011.09.032

Rajendran, R., Minqin, R., Ronald, J. A., Rutt, B. K., Halliwell, B., and Watt, F. (2012). Does iron inhibit calcification during atherosclerosis? Free Radic. Biol. Med. 53, 1675-1679. doi: 10.1016/j.freeradbiomed.2012.07.014

Ramakrishna, G., Rooke, T. W., and Cooper, L. T. (2003). Iron and peripheral arterial disease: revisiting the iron hypothesis in a different light. Vasc. Med. 8, 203-210. doi: 10.1191/1358863x03vm493ra

Rasmussen, M. L., Folsom, A. R., Catellier, D. J., Tsai, M. Y., Garg, U., and Eckfeldt, J. H. (2001). A prospective study of coronary heart disease and the hemochromatosis gene (HFE) C282Y mutation: the Atherosclerosis Risk in Communities (ARIC) study. Atherosclerosis 154, 739-746. doi: 10.1016/S0021-9150(00) 00623-7
Recalcati, S., Locati, M., Marini, A., Santambrogio, P., Zaninotto, F., De Pizzol, M., et al. (2010). Differential regulation of iron homeostasis during human macrophage polarized activation. Eur. J. Immunol. 40, 824-835. doi: 10.1002/eji.200939889

Roest, M., Van Der Schouw, Y. T., De Valk, B., Marx, J. J., Tempelman, M. J., De Groot, P. G., et al. (1999). Heterozygosity for a hereditary hemochromatosis gene is associated with cardiovascular death in women. Circulation 100, 1268-1273. doi: 10.1161/01.CIR.100.12.1268

Rooyakkers, T. M., Stroes, E. S., Kooistra, M. P., Van Faassen, E. E., Hider, R. C., Rabelink, T. J., et al. (2002). Ferric saccharate induces oxygen radical stress and endothelial dysfunction in vivo. Eur. J. Clin. Invest. 32(Suppl. 1), 9-16. doi: 10.1046/j.1365-2362.2002.0320s1009.x

Rother, R. P., Bell, L., Hillmen, P., and Gladwin, M. T. (2005). The clinical sequelae of intravascular hemolysis and extracellular plasma hemoglobin: a novel mechanism of human disease. JAMA 293, 1653-1662. doi: 10.1001/jama. 293.13.1653

Rothman, S. M., Fulling, K. H., and Nelson, J. S. (1986). Sickle cell anemia and central nervous system infarction: a neuropathological study. Ann. Neurol. 20, 684-690. doi: 10.1002/ana.410200606

Sacco, R. L., Boden-Albala, B., Gan, R., Chen, X., Kargman, D. E., Shea, S., et al. (1998). Stroke incidence among white, black, and Hispanic residents of an urban community: the Northern Manhattan Stroke Study. Am. J. Epidemiol. 147, 259-268. doi: 10.1093/oxfordjournals.aje.a009445

Sachais, B. S., Turrentine, T., Dawicki Mckenna, J. M., Rux, A. H., Rader, D., and Kowalska, M. A. (2007). Elimination of platelet factor 4 (PF4) from platelets reduces atherosclerosis in $\mathrm{C} 57 \mathrm{Bl} / 6$ and apoE-/- mice. Thromb. Haemost. 98, 1108-1113. doi: 10.1160/TH07-04-0271

Saeed, O., Otsuka, F., Polavarapu, R., Karmali, V., Weiss, D., Davis, T., et al. (2012). Pharmacological suppression of hepcidin increases macrophage cholesterol efflux and reduces foam cell formation and atherosclerosis. Arterioscler. Thromb. Vasc. Biol. 32, 299-307. doi: 10.1161/ATVBAHA.111.240101

Sakakura, K., Nakano, M., Otsuka, F., Ladich, E., Kolodgie, F. D., and Virmani, R. (2013). Pathophysiology of atherosclerosis plaque progression. Heart Lung Circ. 22, 399-411. doi: 10.1016/j.hlc.2013.03.001

Sallam, T., Cheng, H., Demer, L. L., and Tintut, Y. (2013). Regulatory circuits controlling vascular cell calcification. Cell. Mol. Life Sci. 70, 3187-3197. doi: 10.1007/s00018-012-1231-y

Salonen, J. T., Nyyssonen, K., Korpela, H., Tuomilehto, J., Seppanen, R., and Salonen, R. (1992). High stored iron levels are associated with excess risk of myocardial infarction in eastern Finnish men. Circulation 86, 803-811. doi: 10.1161/01.CIR.86.3.803

Salonen, J. T., Tuomainen, T. P., Salonen, R., Lakka, T. A., and Nyyssonen, K. (1998). Donation of blood is associated with reduced risk of myocardial infarction. The Kuopio ischaemic heart disease risk factor study. Am. J. Epidemiol. 148, 445-451. doi: 10.1093/oxfordjournals.aje.a009669

Schwartz, S. M., Galis, Z. S., Rosenfeld, M. E., and Falk, E. (2007). Plaque rupture in humans and mice. Arterioscler. Thromb. Vasc. Biol. 27, 705-713. doi: 10.1161/01.ATV.0000261709.34878.20

Schwertner, H. A., Jackson, W. G., and Tolan, G. (1994). Association of low serum concentration of bilirubin with increased risk of coronary artery disease. Clin. Chem. 40, 18-23.

Shen, Y., Ward, N. C., Hodgson, J. M., Puddey, I. B., Wang, Y., Zhang, D., et al. (2013). Dietary quercetin attenuates oxidant-induced endothelial dysfunction and atherosclerosis in apolipoprotein E knockout mice fed a high-fat diet: a critical role for heme oxygenase-1. Free Radic. Biol. Med. 65, 908-915. doi: 10.1016/j.freeradbiomed.2013.08.185

Silva, G., Jeney, V., Chora, A., Larsen, R., Balla, J., and Soares, M. P. (2009). Oxidized hemoglobin is an endogenous proinflammatory agonist that targets vascular endothelial cells. J. Biol. Chem. 284, 29582-29595. doi: 10.1074/jbc.M109.045344

Silva, M., Silva, M. E., De Paula, H., Carneiro, C. M., and Pedrosa, M. L. (2008). Iron overload alters glucose homeostasis, causes liver steatosis, and increases serum triacylglycerols in rats. Nutr. Res. 28, 391-398. doi: 10.1016/j.nutres.2008.02.009

Sindrilaru, A., Peters, T., Wieschalka, S., Baican, C., Baican, A., Peter, H., et al. (2011). An unrestrained proinflammatory M1 macrophage population induced by iron impairs wound healing in humans and mice. J. Clin. Invest. 121, 985-997. doi: 10.1172/JCI44490

Singleton, J. W., and Laster, L. (1965). Biliverdin reductase of guinea pig liver. J. Biol. Chem. 240, 4780-4789. 
Siow, R. C., Sato, H., and Mann, G. E. (1999). Heme oxygenase-carbon monoxide signalling pathway in atherosclerosis: anti-atherogenic actions of bilirubin and carbon monoxide? Cardiovasc. Res. 41, 385-394. doi: 10.1016/S00086363(98)00278-8

Smith, C., Mitchinson, M. J., Aruoma, O. I., and Halliwell, B. (1992). Stimulation of lipid peroxidation and hydroxyl-radical generation by the contents of human atherosclerotic lesions. Biochem. J. 286(pt 3), 901-905.

Smith, J. D., Trogan, E., Ginsberg, M., Grigaux, C., Tian, J., and Miyata, M. (1995). Decreased atherosclerosis in mice deficient in both macrophage colonystimulating factor (op) and apolipoprotein E. Proc. Natl. Acad. Sci. U.S.A. 92, 8264-8268. doi: 10.1073/pnas.92.18.8264

Solanas-Barca, M., Mateo-Gallego, R., Calmarza, P., Jarauta, E., Bea, A. M., Cenarro, A., et al. (2009). Mutations in HFE causing hemochromatosis are associated with primary hypertriglyceridemia. J. Clin. Endocrinol. Metab. 94, 4391-4397. doi: 10.1210/jc.2009-0814

Sripetchwandee, J., Pipatpiboon, N., Chattipakorn, N., and Chattipakorn, S. (2014). Combined therapy of iron chelator and antioxidant completely restores brain dysfunction induced by iron toxicity. PLOS ONE 9:e85115. doi: 10.1371/journal.pone.0085115

Stadler, N., Lindner, R. A., and Davies, M. J. (2004). Direct detection and quantification of transition metal ions in human atherosclerotic plaques: evidence for the presence of elevated levels of iron and copper. Arterioscler. Thromb. Vasc. Biol. 24, 949-954. doi: 10.1161/01.ATV.0000124892.90999.cb

Stoneman, V., Braganza, D., Figg, N., Mercer, J., Lang, R., Goddard, M., et al. (2007). Monocyte/macrophage suppression in CD11b diphtheria toxin receptor transgenic mice differentially affects atherogenesis and established plaques. Circ. Res. 100, 884-893. doi: 10.1161/01.RES.0000260802.75766.00

Sullivan, J. L. (1981). Iron and the sex difference in heart disease risk. Lancet 1, 1293-1294. doi: 10.1016/S0140-6736(81)92463-6

Sullivan, J. L. (1989). The iron paradigm of ischemic heart disease. Am. Heart J. 117, 1177-1188. doi: 10.1016/0002-8703(89)90887-9

Sullivan, J. L. (1991). Blood donation may be good for the donor. Iron, heart disease, and donor recruitment. Vox Sang. 61, 161-164. doi: 10.1111/j.14230410.1991.tb00940.x

Sullivan, J. L. (2009). Iron in arterial plaque: modifiable risk factor for atherosclerosis. Biochim. Biophys. Acta 1790, 718-723. doi: 10.1016/j.bbagen.2008.06.005

Sullivan, J. L., and Katz, S. D. (2007). Iron reduction and cardiovascular outcomes. JAMA 297, 2075-2076. doi: 10.1001/jama.297.19.2075-a

Sullivan, J. L., and Zacharski, L. R. (2001). Hereditary haemochromatosis and the hypothesis that iron depletion protects against ischemic heart disease. Eur. J. Clin. Invest. 31, 375-377. doi: 10.1046/j.1365-2362.2001.00830.x

Sun, L., Franco, O. H., Hu, F. B., Cai, L., Yu, Z., Li, H., et al. (2008). Ferritin concentrations, metabolic syndrome, and type 2 diabetes in middle-aged and elderly chinese. J. Clin. Endocrinol. Metab. 93, 4690-4696. doi: 10.1210/jc.2008-1159

Switzer, J. A., Hess, D. C., Nichols, F. T., and Adams, R. J. (2006). Pathophysiology and treatment of stroke in sickle-cell disease: present and future. Lancet Neurol. 5, 501-512. doi: 10.1016/S1474-4422(06)70469-0

Syrovatka, P., Kraml, P., Hulikova, K., Fialova, L., Vejrazka, M., Crkovska, J., et al. (2011). Iron stores are associated with asymptomatic atherosclerosis in healthy men of primary prevention. Eur. J. Clin. Invest. 41, 846-853. doi: 10.1111/j.13652362.2011.02474.x

Tantawy, A. A., Adly, A. A., El Maaty, M. G., and Amin, S. A. (2009). Subclinical atherosclerosis in young beta-thalassemia major patients. Hemoglobin 33, 463-474. doi: 10.3109/03630260903343616

Tenhunen, R., Marver, H. S., and Schmid, R. (1968). The enzymatic conversion of heme to bilirubin by microsomal heme oxygenase. Proc. Natl. Acad. Sci. U.S.A. 61, 748-755. doi: 10.1073/pnas.61.2.748

Tolosano, E., Fagoonee, S., Morello, N., Vinchi, F., and Fiorito, V. (2010). Heme scavenging and the other facets of hemopexin. Antioxid. Redox Signal. 12, 305-320. doi: 10.1089/ars.2009.2787

Tuomainen, T. P., Kontula, K., Nyyssonen, K., Lakka, T. A., Helio, T., and Salonen, J. T. (1999). Increased risk of acute myocardial infarction in carriers of the hemochromatosis gene Cys282Tyr mutation: a prospective cohort study in men in eastern Finland. Circulation 100, 1274-1279. doi: 10.1161/01.CIR.100.12.1274

Tuomainen, T. P., Punnonen, K., Nyyssonen, K., and Salonen, J. T. (1998). Association between body iron stores and the risk of acute myocardial infarction in men. Circulation 97, 1461-1466. doi: 10.1161/01.CIR.97.15.1461
Tuomainen, T. P., Salonen, R., Nyyssonen, K., and Salonen, J. T. (1997). Cohort study of relation between donating blood and risk of myocardial infarction in 2682 men in eastern Finland. BMJ 314, 793-794. doi: 10.1136/bmj.314.7083.793

Valenti, L., Dongiovanni, P., Motta, B. M., Swinkels, D. W., Bonara, P., Rametta, R., et al. (2011a). Serum hepcidin and macrophage iron correlate with MCP-1 release and vascular damage in patients with metabolic syndrome alterations. Arterioscler. Thromb. Vasc. Biol. 31, 683-690. doi: 10.1161/ATVBAHA.110.214858

Valenti, L., Swinkels, D. W., Burdick, L., Dongiovanni, P., Tjalsma, H., Motta, B. M., et al. (2011b). Serum ferritin levels are associated with vascular damage in patients with nonalcoholic fatty liver disease. Nutr. Metab. Cardiovasc. Dis. 21, 568-575. doi: 10.1016/j.numecd.2010.01.003

Van Tits, L. J., Jacobs, E. M., Swinkels, D. W., Lemmers, H. L., Van Der Vleuten, G. M., De Graaf, J., et al. (2007). Non-transferrin-bound iron is associated with plasma level of soluble intercellular adhesion molecule-1 but not with in vivo low-density lipoprotein oxidation. Atherosclerosis 194, 272-278. doi: 10.1016/j.atherosclerosis.2006.08.012

Vichinsky, E. P. (2005). Changing patterns of thalassemia worldwide. Ann. N.Y. Acad. Sci. 1054, 18-24. doi: 10.1196/annals.1345.003

Vinchi, F., De Franceschi, L., Ghigo, A., Townes, T., Cimino, J., Silengo, L., et al. (2013). Hemopexin therapy improves cardiovascular function by preventing heme-induced endothelial toxicity in mouse models of hemolytic diseases. Circulation 127, 1317-1329. doi: 10.1161/CIRCULATIONAHA.112.130179

Vinchi, F., Gastaldi, S., Silengo, L., Altruda, F., and Tolosano, E. (2008). Hemopexin prevents endothelial damage and liver congestion in a mouse model of heme overload. Am. J. Pathol. 173, 289-299. doi: 10.2353/ajpath.2008. 071130

Vinchi, F., and Tolosano, E. (2013). Therapeutic approaches to limit hemolysisdriven endothelial dysfunction: scavenging free heme to preserve vasculature homeostasis. Oxid. Med. Cell. Longev. 2013:396527. doi: 10.1155/2013/ 396527

Virmani, R., Kolodgie, F. D., Burke, A. P., Finn, A. V., Gold, H. K., Tulenko, T. N., et al. (2005). Atherosclerotic plaque progression and vulnerability to rupture: angiogenesis as a source of intraplaque hemorrhage. Arterioscler. Thromb. Vasc. Biol. 25, 2054-2061. doi: 10.1161/01.ATV.0000178991.71605.18

Vukovic, I., Arsenijevic, N., Lackovic, V., and Todorovic, V. (2006). The origin and differentiation potential of smooth muscle cells in coronary atherosclerosis. Exp. Clin. Cardiol. 11, 123-128.

Wang, H., Luo, W., Wang, J., Guo, C., Wolffe, S. L., Sun, E. B., et al. (2013). Paradoxical protection from atherosclerosis and thrombosis in a mouse model of sickle cell disease. Br. J. Haematol. 162, 120-129. doi: 10.1111/bjh.12342

Watari, Y., Yamamoto, Y., Brydun, A., Ishida, T., Mito, S., Yoshizumi, M., et al. (2008). Ablation of the bachl gene leads to the suppression of atherosclerosis in bach1 and apolipoprotein E double knockout mice. Hypertens. Res. 31, 783-792. doi: 10.1291/hypres.31.783

Wong, C. M., Preston, I. R., Hill, N. S., and Suzuki, Y. J. (2012). Iron chelation inhibits the development of pulmonary vascular remodeling. Free Radic. Biol. Med. 53, 1738-1747. doi: 10.1016/j.freeradbiomed.2012.08.576

Wu, B. J., Kathir, K., Witting, P. K., Beck, K., Choy, K., Li, C., et al. (2006). Antioxidants protect from atherosclerosis by a heme oxygenase-1 pathway that is independent of free radical scavenging. J. Exp. Med. 203, 1117-1127. doi: 10.1084/jem.20052321

Yachie, A., Niida, Y., Wada, T., Igarashi, N., Kaneda, H., Toma, T., et al. (1999). Oxidative stress causes enhanced endothelial cell injury in human heme oxygenase-1 deficiency. J. Clin. Invest. 103, 129-135. doi: 10.1172/JCI4165

Yet, S. F., Layne, M. D., Liu, X., Chen, Y. H., Ith, B., Sibinga, N. E., et al. (2003). Absence of heme oxygenase-1 exacerbates atherosclerotic lesion formation and vascular remodeling. FASEB J. 17, 1759-1761. doi: 10.1096/fj.03-0187fje

You, S. A., Archacki, S. R., Angheloiu, G., Moravec, C. S., Rao, S., Kinter, M., et al. (2003). Proteomic approach to coronary atherosclerosis shows ferritin light chain as a significant marker: evidence consistent with iron hypothesis in atherosclerosis. Physiol. Genomics 13, 25-30. doi: 10.1152/physiolgenomics.00124.2002

Yuan, X. M., Anders, W. L., Olsson, A. G., and Brunk, U. T. (1996). Iron in human atheroma and LDL oxidation by macrophages following erythrophagocytosis. Atherosclerosis 124, 61-73. doi: 10.1016/0021-9150(96)05817-0

Zacharski, L. R., Chow, B. K., Howes, P. S., Shamayeva, G., Baron, J. A., Dalman, R. L., et al. (2007). Reduction of iron stores and cardiovascular outcomes in 
patients with peripheral arterial disease: a randomized controlled trial. JAMA 297, 603-610. doi: 10.1001/jama.297.6.603

Zacharski, L. R., Ornstein, D. L., Woloshin, S., and Schwartz, L. M. (2000). Association of age, sex, and race with body iron stores in adults: analysis of NHANES III data. Am. Heart J. 140, 98-104. doi: 10.1067/mhj.2000.106646

Zarjou, A., Jeney, V., Arosio, P., Poli, M., Antal-Szalmas, P., Agarwal, A., et al. (2009). Ferritin prevents calcification and osteoblastic differentiation of vascular smooth muscle cells. J. Am. Soc. Nephrol. 20, 1254-1263. doi: 10.1681/ASN.2008070788

Zenke-Kawasaki, Y., Dohi, Y., Katoh, Y., Ikura, T., Ikura, M., Asahara, T., et al. (2007). Heme induces ubiquitination and degradation of the transcription factor Bach1. Mol. Cell. Biol. 27, 6962-6971. doi: 10.1128/MCB.02415-06

Zhang, W. J., and Frei, B. (2003). Intracellular metal ion chelators inhibit TNFalpha-induced SP- 1 activation and adhesion molecule expression in human aortic endothelial cells. Free Radic. Biol. Med. 34, 674-682. doi: 10.1016/S08915849(02)01375-8

Zhang, W. J., Wei, H., and Frei, B. (2010). The iron chelator, desferrioxamine, reduces inflammation and atherosclerotic lesion development in experimental mice. Exp. Biol. Med. 235, 633-641. doi: 10.1258/ebm.2009.009229

Zheng, H., Cable, R., Spencer, B., Votto, N., and Katz, S. D. (2005). Iron stores and vascular function in voluntary blood donors. Arterioscler. Thromb. Vasc. Biol. 25, 1577-1583. doi: 10.1161/01.ATV.0000174126.28201.61
Zohn, I. E., De Domenico, I., Pollock, A., Ward, D. M., Goodman, J. F., Liang, X., et al. (2007). The flatiron mutation in mouse ferroportin acts as a dominant negative to cause ferroportin disease. Blood 109, 4174-4180. doi: 10.1182/blood-2007-01-066068

Conflict of Interest Statement: The authors declare that the research was conducted in the absence of any commercial or financial relationships that could be construed as a potential conflict of interest.

Received: 25 February 2014; paper pending published: 23 March 2014; accepted: 14 April 2014; published online: 05 May 2014

Citation: Vinchi F, Muckenthaler MU, Da Silva MC, Balla G, Balla J and Jeney V (2014) Atherogenesis and iron: from epidemiology to cellular level. Front. Pharmacol. 5:94. doi: 10.3389/fphar.2014.00094

This article was submitted to Drug Metabolism and Transport, a section of the journal Frontiers in Pharmacology.

Copyright () 2014 Vinchi, Muckenthaler, Da Silva, Balla, Balla and Jeney. This is an open-access article distributed under the terms of the Creative Commons Attribution License (CC BY). The use, distribution or reproduction in other forums is permitted, provided the original author(s) or licensor are credited and that the original publication in this journal is cited, in accordance with accepted academic practice. No use, distribution or reproduction is permitted which does not comply with these terms. 